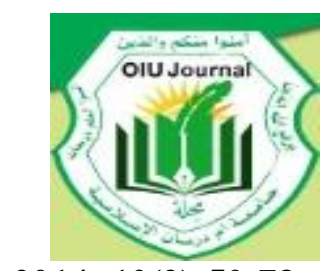

2014; 10(2):50-73

د. جعفر خلف الله شبو"
Omdurman Islamic University Journal(OIUJ)

\author{
مجلة جامعة أم درمان الاسلامية
}

https://journal.oiu.edu.sd/index.php/oiuj https://doi.org/10.52981/oiuj.v10i2.1656

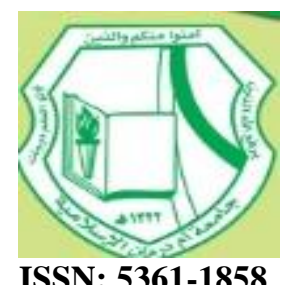

ISSN: 5361-1858

\title{
استراتيجية قريش في صنع السلام والمحافظة عليه
}

مستخلص البحث

طوت قبيلة قريش صفحة البداوة عندما استقرت بمكة المكرمة حوالي منتصف القرن الرابع الميلادي. وبحكم جغرافية المكان أدركت قريش أن التجارة هي قوام حياتها في تلك المنطقة القاحلة، ولكن لا قوام للتجارة دون توفر الأمن والسلام. فلم يتخر القرشيون وسعا في طلبهما عن طريق خطة إستراتيجية بديعة لصنع السلام والمحافظة عليه في آن واحد.

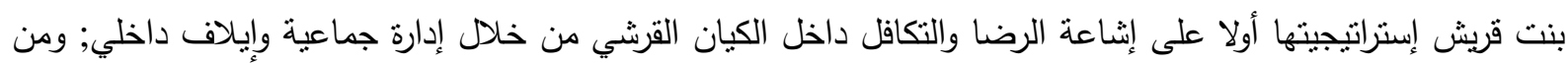

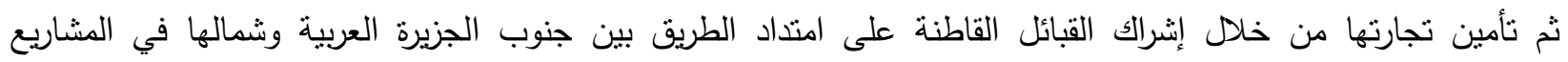

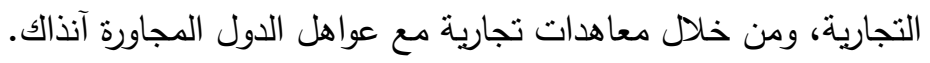

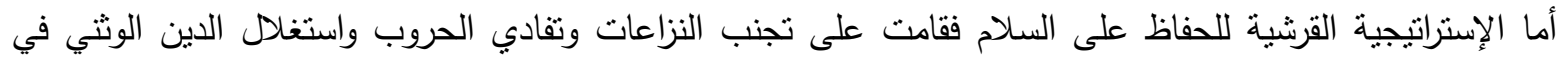

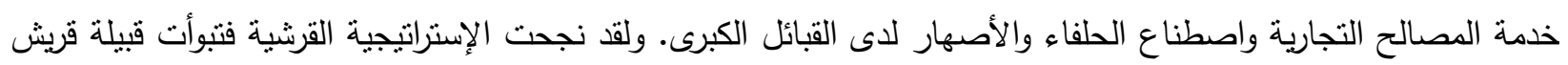
مرتبة مرموقة أهلتها لتأسيس دولة عظمى تحت ظلال الإسلام الوارفة في القرن السابع الميلادي.

\section{Abstract}

Around the $2^{\text {nd }}$ half of the $4^{\text {th }}$ century, the tribe of Qureish gathered in the holly city of Makkah. As the region was dry, arid and dehydrated, trade was the only possible profession but it required peace and security which were difficult to attain. Qureish needed to build a special strategy to achieve peace at that bloody time.

Qureish designed it strategy to realize satisfaction and solidarity among the tribe people throw setting up a collective administration and an internal Ellaf (docility). The strategy included avoiding conflicts and wars, utilizing the pagan religion in the service of trade, forming allies and concluded marriages with the big Arabic tribes. Although it was not an easy task, the Qureishis strategy succeeded and the tribe became a prominent figure in Arabia. The ripe fruit of that endeavor work was the establishing of the great Islamic State under the shades of Islam in the $7^{\text {th }}$ century AD. 
مقدمة:

لعب مناخ منطقة الحجاز القاري وتربتها الرملية الصخرية وشح مياهها وموقعها المتوسط بين أقدم الحضارات دوراً جوهرياً

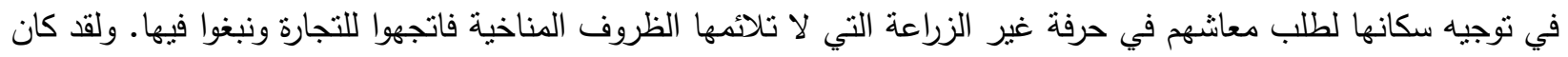
القرشيون أعظم أهل الحجاز كسباً في هذا الثأن لوجودهم بمكة المكرمة حاضرة تجارة العرب قبل الإسلام ومحجها الأكبر،

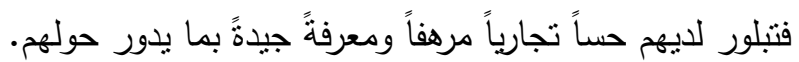
أدرك القرشيون مبكراً أن التجارة لا يمكن أن تزدهر وتثمر إلا في محيط مستقر وآمن، وكانت جزيرة العرب آنذاك أبعد ما تكون عن الأمن والسلام والاستقرار؛ لم بستسلم القرشيون للأمر الواقع فنشطوا لجلب السلام على عدة محاور ، وعقدوا الاتفاقيات

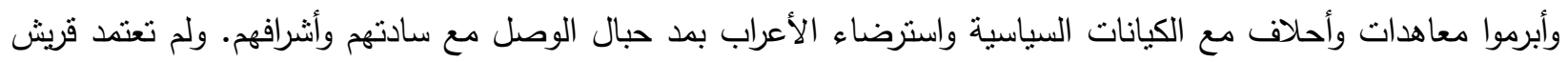

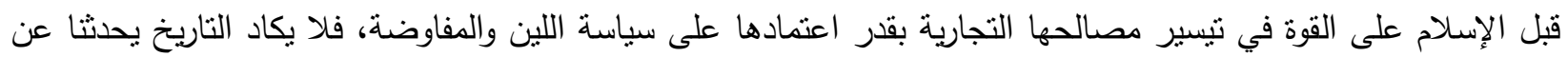
حروب حقيقة خاضتها قريش اللهم إلا حروب الفجار التي كانت في معظمها مناوشات تتتهي بالصلح، كما أن مكة المكرمة

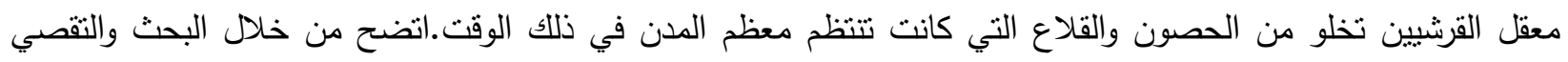
واستكناه المصادر أن القرشيين في سعيهم الدؤوب لإرساء قواعد السلم والمحافظة عليه، انطلقوا من إستراتيجية واضحة المعالم

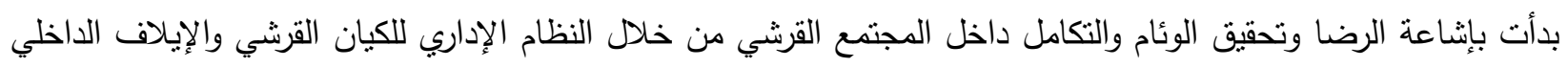

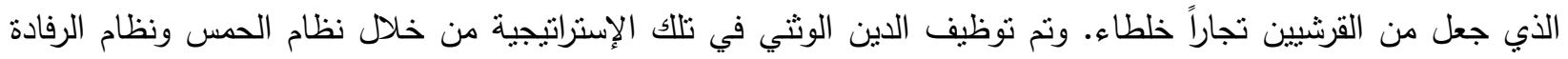

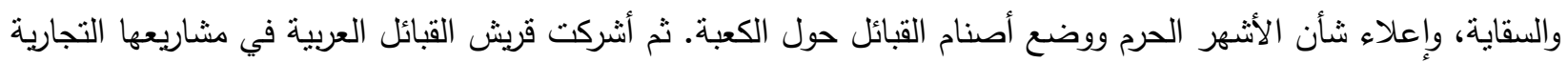

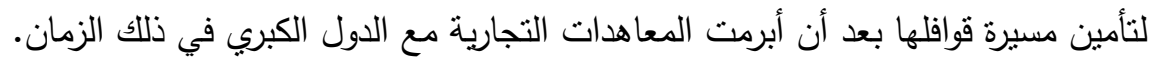

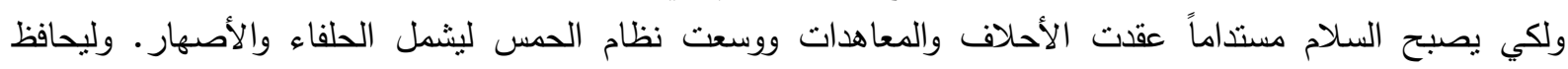
القرشيون على كسبهم المادي والمعنوي عقدوا حلف الفضول الذي حفظ للمدينة المقدة سمعتها الطيبة وللقرشيين مكانتهم السامية ضمن إستراتيجية قريش في صنع السلام وحفظه. جاء هذا البحث في إستراتيجية قريش في صنع السلام وحفظه في

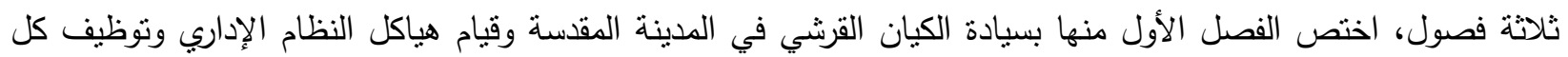

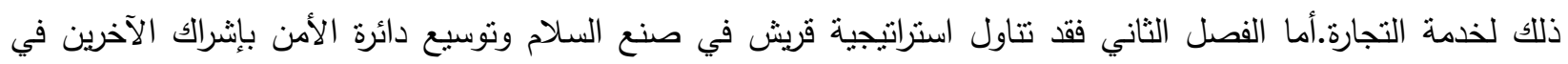

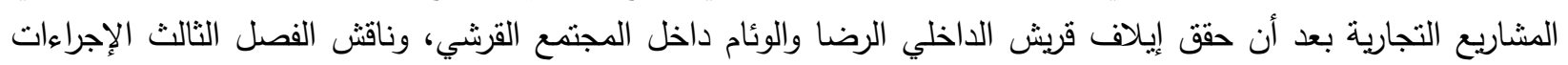

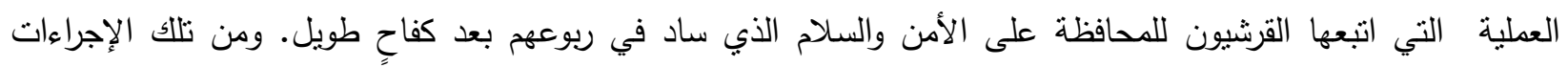

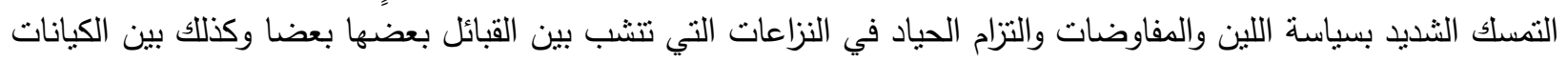
السياسية ذات الصلة بتجارتهم. كما أبرموا الأحلاف للتصدي الجماعي للمنحرفين والخارجين على روح الإستراتيجية السلمية. واختتم البحث بإبراز النتائج المهمة التي توصل إليها الباحث مع إيراد عددٍ من النوصيات التي تخدم قضية البحث العلمي في هذا المضمار . 


\section{الفصل الأول}

\section{قيام الكيان القرشي}

المبحث الأول: سيادة قريش على البيت الحرام

يرى غالبية المؤرخين أن شهرة مكة كبلد مقدس أخذت نتبلور على عهد الفطوريين، وهم العماليق عند أهل الأخبار، فقد

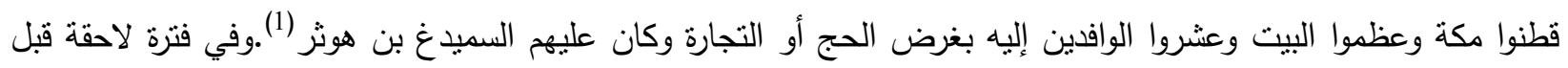

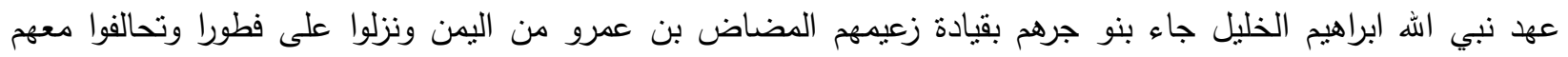

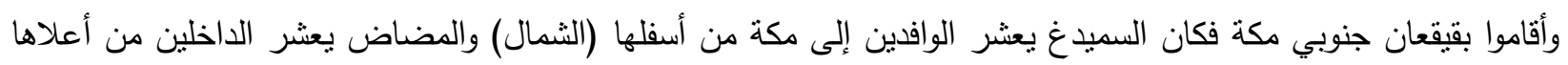

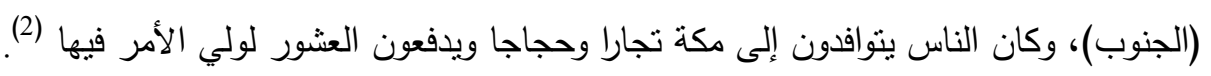

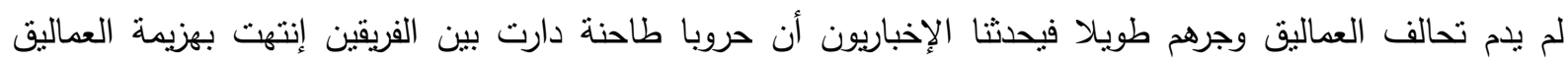

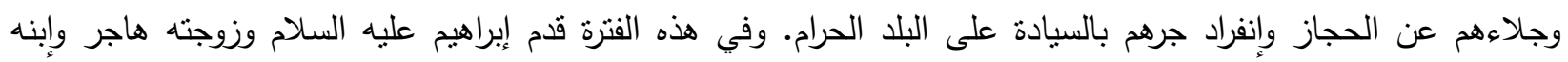

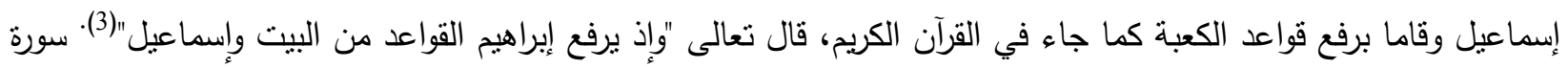
البقرة آية 127.

وتزوج إسماعيل ببنت الحارث بن مضاض سيد جرهم ومنهت كان نسله وهم العدنانيون وإليهم تنتسب قبيلة قريش. وقبيل

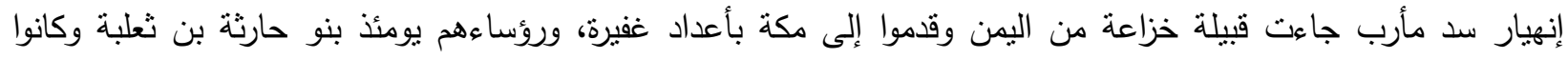

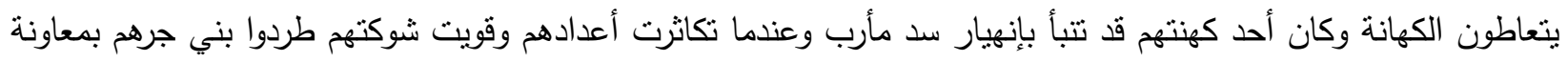

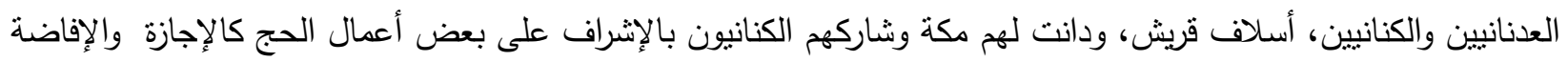

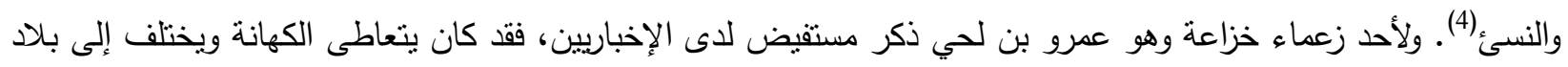

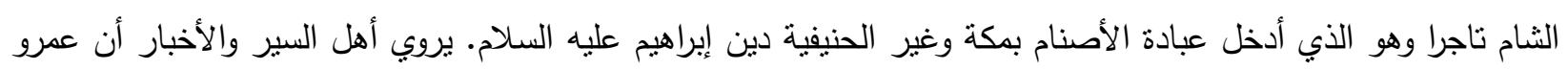

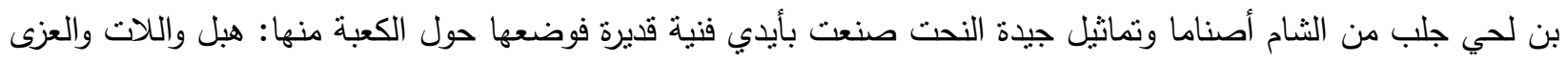

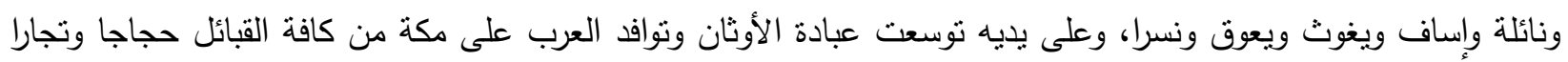

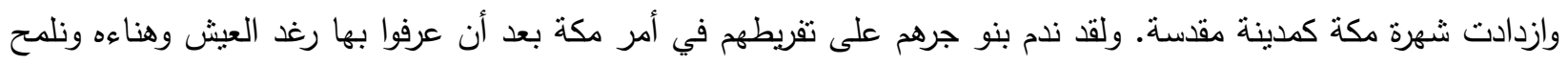

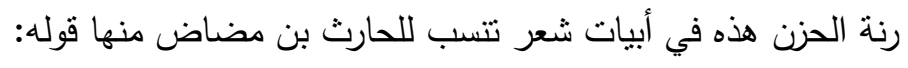
وكنا ولات البيت والقاطن الذي في لتصن

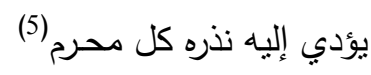

ولأهل الأخبار روايات متعددة في تعليل كثرة أسماء مكة ومن زارها معظما من ملوك الأرض وذكروا فئرة فئه الإسكندر الأكبر

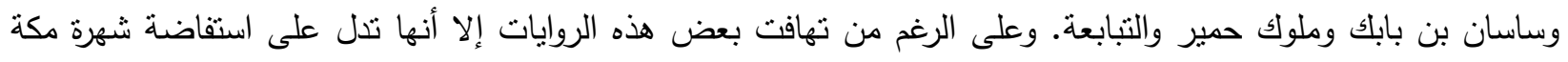
وعلو مكانتها. أما قريش ققد بدأت شوكثها تقوى على عهد كعب بن لؤي الجد الثالث لقصي بن كلاب، فتنكر المصادر أنه كان رئيسا مقدما

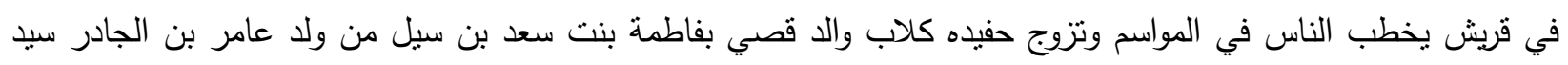

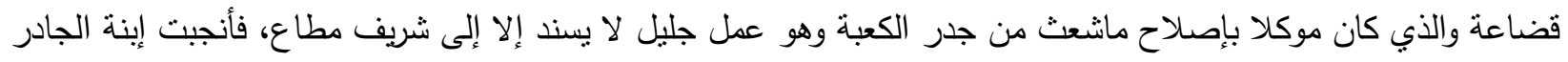

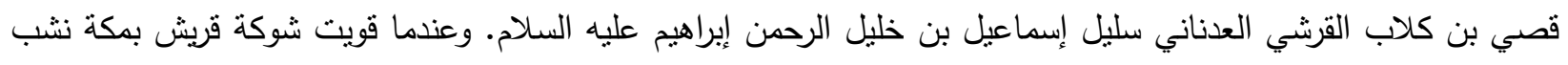

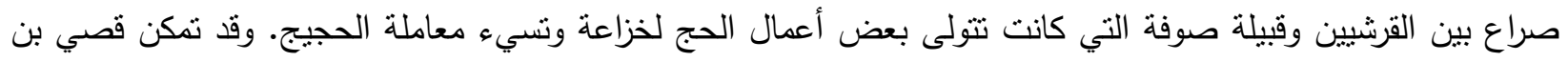


كلاب من الحصول على تأييد ودعم بني كنانة و أصهاره من قضاعة وبني عذرة وهم من القبائل اليمنية التي استوطنت الثام

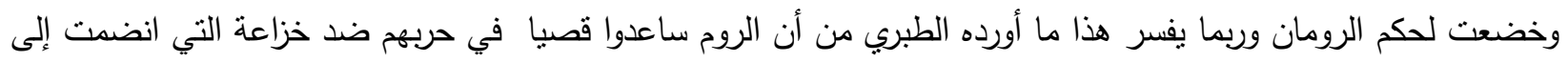
قبيلة صوفة. فألحق قصي وحلفاءه بخزاعة هزيمة ساحقة وأجلوهم عن مكة. أما الرواية الثائعة حول صفقة أبي غبشان الخزاعي الذي باع لقصي حق قبيلته في الولاية على البيت بزق خمر وقعود فلا تفسر كل الأمر. وعندنا تداعى الناس للصلح حكما في الدماء عمرو بن بكر بن عبد مناة فحكم بحق قصي في الولاية على البيت، وشدخ الدماء التي أصابها قصي من

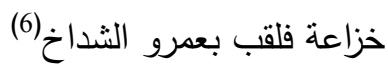
بعد أن تمت الغلبة لقصي على خزاعة، جمع قومه من الثعاب والأودية والجبال إلى مكة فبنوا المساكن وأقاموا بها وكان من قبلهم لايبيتون بمكة بل يكونون بها نهارا فقط، فلم يكن بككة مبيت قبل قصي بن كلاب(7). ولقد قام قصي بن كندة كلاب بأعمال

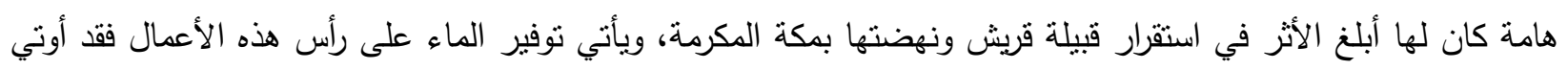
الرجل إلى جانب مواهبه الكثيرة ملكة اكتشاف أماكن الماء في باطن الأرض وهي ملكة ظلت تعرف لأبناء قصي وأحفاده، فقد ورثها عنه ابنه عبد مناف وحفيده عبد المطلب الذي اكتشف بئر زمزم قبيل مولد النبي محمد صلى الله عليه وسلم.حفر قصي الهي الهي الآبار داخل مكة بعد أن كانت تشرب من خارجها (8). وتذكر المصادر أن قصيا جدد بناء الكعبة وسقفها بخشب الدوم وجريد النخل ووقف بمزدلفة وأوقد بها النار ليراها من دفع من عرفة ومازال إيقاد النار بمزدلفة سنة ماضية إلى يومنا هذا.

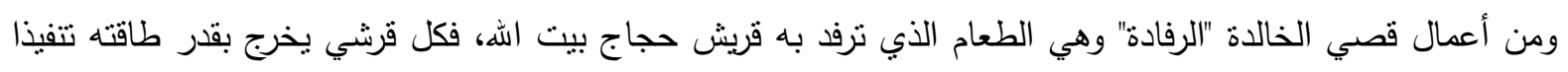
لطلب قصي الذي قال لهم: "يامعشر قريش إنكم جيران اله وأهل مكة والحرم وإن الحجيج ضيوف اله وزوار بيته وهم أحق بقاج

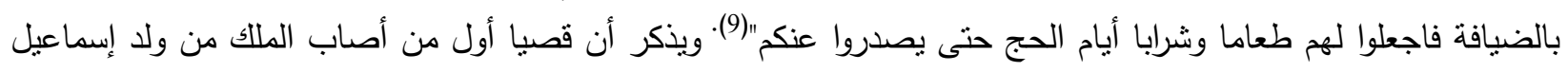
فكان معاصرا لأيام النعمان بن المنذر ملك الحيرة وبهرام بن جور إمبراطور الفرس في النصف الأول من القرن الخامس الميلادي. يعد قصي بن كلاب المؤسس للكيان القرشي، الجد الخامس لسيدنا محمد صلى الله عليه وسلم، فقد جمع قريش من بطون فهر

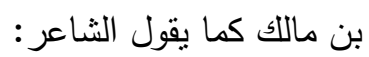

\section{قصي أبوكم من يسمى مجمعا}

به جمع الله القبائل من فهر

فإلى قصي يرجع الفضل في جمع قريش وترتيبها على منازلها بمكة، فقريش البطاح هم البطون التي نزلت بطحاء مكة أي بطن واديها وهم بنو عبد مناف وبنو عبد الدار وبنو عبد العزى وبنو زهرة وبنو تيم وبنو مخزوم وبنو جمح وبنو سهم وبنو

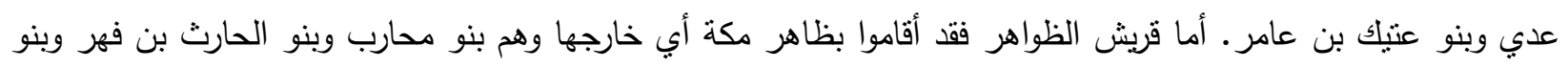
الأدرب بن غالب وبنو هصيص بن عامر ،ويذكر المؤرخ بن خلدون أن قصيا بعد أن استقر بقومه من قريش البطاح بمكة

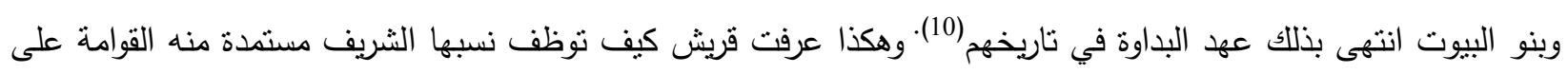
البيت الحرام وتبسط سلطانها الديني على العرب. 


\section{المبحث الثاني \\ النظام الإداري للكيان القرشي}

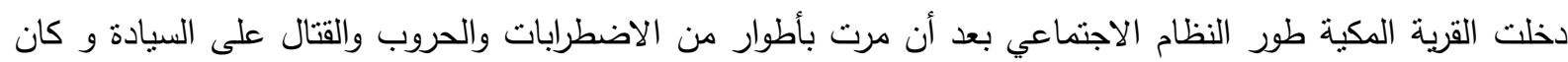

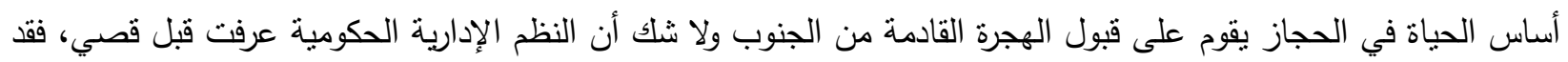

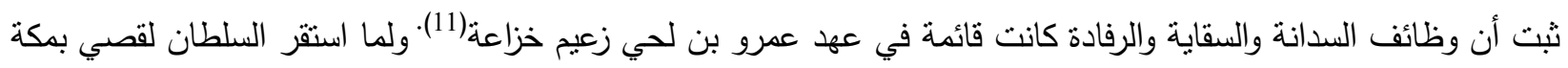

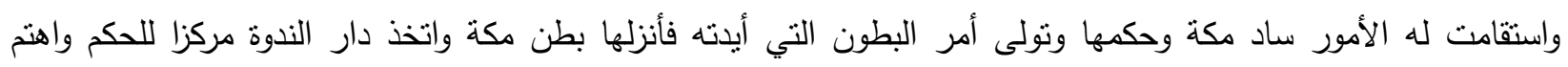

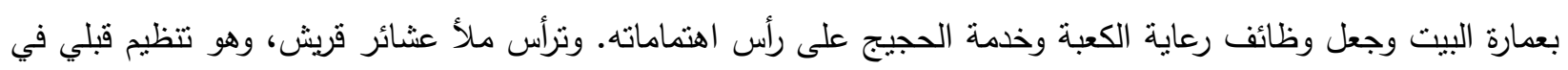

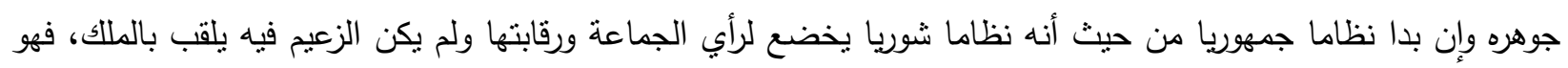

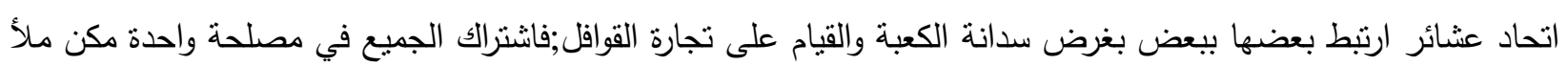

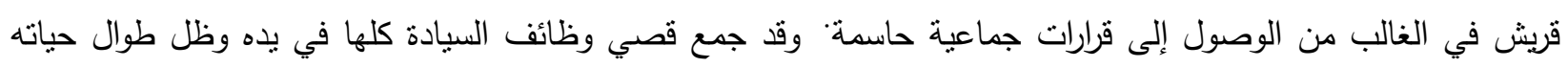
محترما مطاعا برى الناس أمره كالدين المنبع (12). خلف عبد مناف أباه في رئاسة قريش فسار في طريقه واجتهد في إكمال عمله السياسي بنأليف القبائل وعقد الاتفاقيات

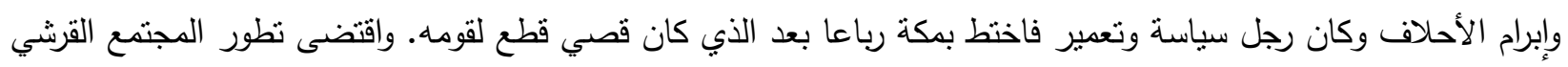

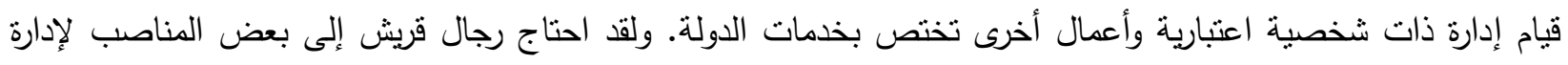

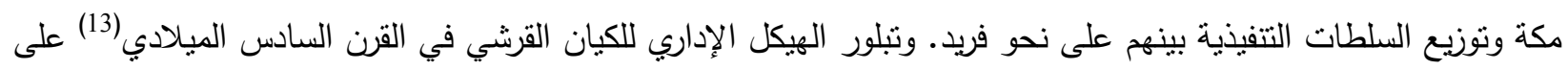

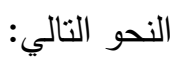

الهيكل الإداري لدولة قريش في القرن السادس الميلادي

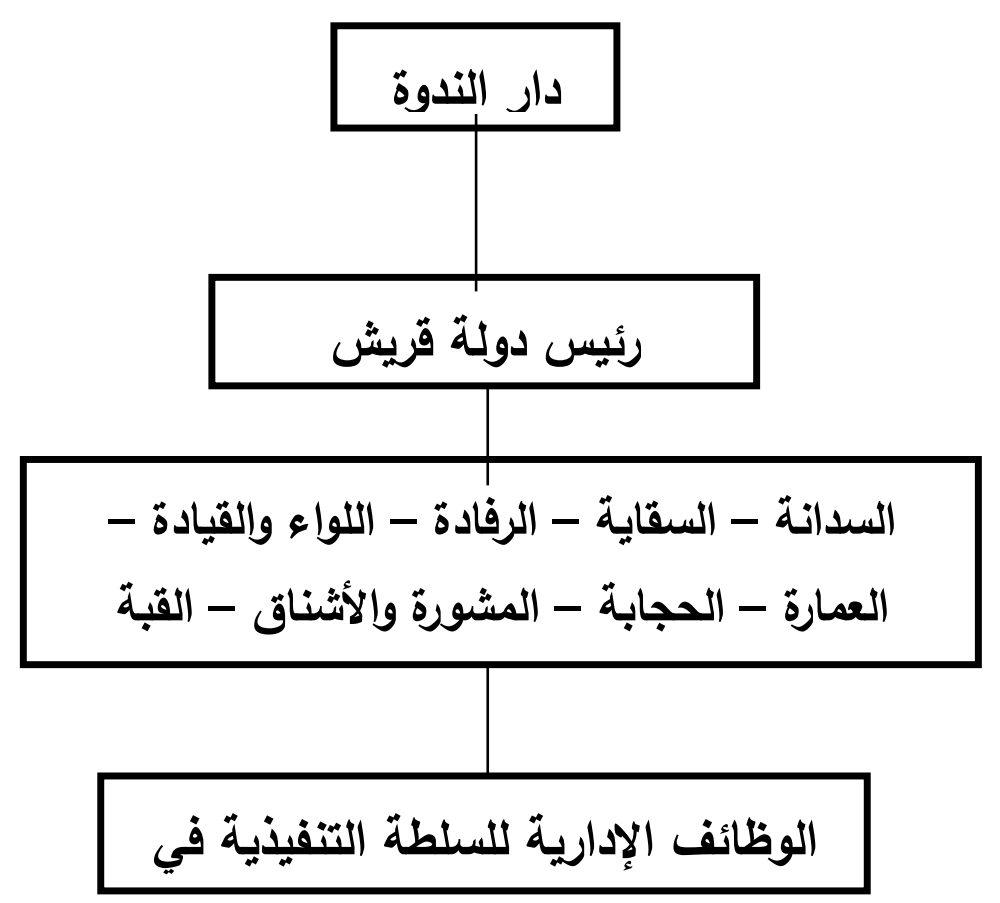


دار الندوة:

هي الدار التي بناها قصي بن كلاب ملاصقة للمسجد الحرام من الجهة الثمالية وكانت فسيحة وفيها كانت قريش تقضي شؤونها العامة، وقد سميث بالندوة لأنهم إذا حزبهم أمر ندوا إليها للنشاور (14). وفيها يجتمع ملأ قريش للنتاور ولم يكن يدخلها لإبداء الرأي والمشورة إلا من تجاوز سن الأربعين وفيها كانت تعقد قريش لواءها إذا خرجت للحرب ومن تلك الدار أيضا كانت

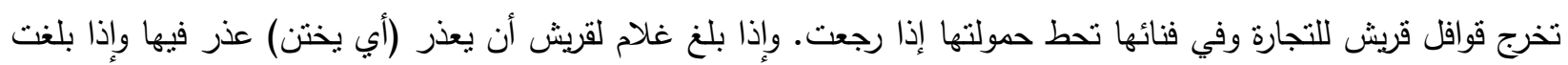

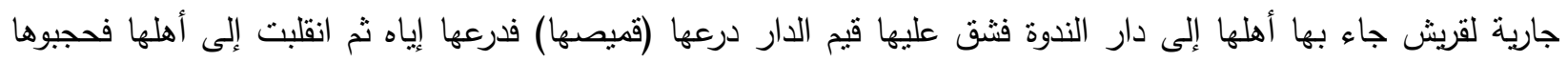
والظاهر أن الغرض من الأمرين الأخيرين هو التعريف بالبالغين من ذكور وإناث قريش ودار الندوة في مكة نتبه الاكليزا في أثنيا إلا أن الملأ القرشي كان اكثر تفاعلا وشعورا بالمسؤولية من رجال الاكليزا اليونانية وأقل تأثرا بالانفعالات العاطفية، ذلك لأن الملأ كان يتكون من رؤساء العشائر أوبي الرأي والحكمة فيها على حين كان الأثنبيون يقبلون في الاكليزا كل رجل أمين مستقيم (15).

السدانة:

هي رعاية البيت والقيام على إعداده للزائرين وفي القاموس السادن هو خادم الكعبة وبيت الأصنام(16). ووظيفة السدانة من

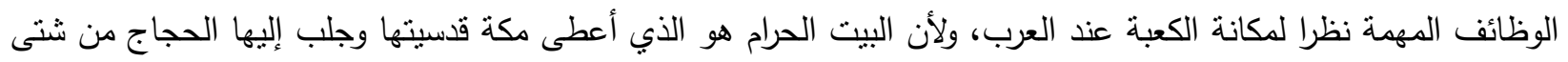
بقاع الأرض، وعلى موسم الحج يقوم جزء كبير من حياة مكة الاقتصادية ولذلك اهتمت قريش برعاية البيت الحرام والدعاية له له في أنحاء الجزيرة وجلبت اليه أصنام القبائل وأقامتها حول الكعبة وروي أن عددها بلغ 360 صنما حطمها النبي صلى الله عليه

وسلم عام فتح مكة(17). السقايةة:

وهي أيضا مرتبطة بالكعبة والحج إليها وتبرز أهميتها في أن مكة بلد شحيحة المياه وأن الحاج إليها يلقى عنتا شديدا إذا لم يتيسر لله الماء خاصة في موسم الحج حيث يكثر الوافدون إلى مكة لأداء هذه المناسك. فقد أصبحت مهمة السقاية بالغة الخطورة خصوصا قبل ظهور بئر زمزم التي يسرت المقام في هذا الوادي الققر والتي كانت قد طمرت نتيجة لإهمال جرهم لها لهاء أو لأن زعيم جرهم قد طمرها بعد أن هزم أمام قبيلة خزاعة واضطر للخروج من مكة حتى يضايق خزاعة ويجعل مهمة الحج

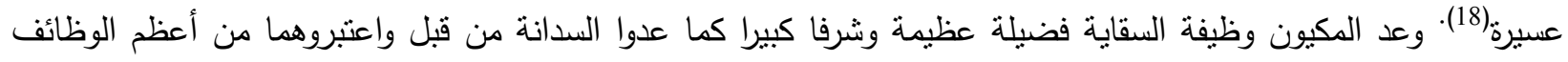
وكانت قريش تفاخر بهما وقد تولت هذين الوظيفتين أعظم العشائر القرشية، وحين فتح النبي مكة ألغى كل المناصب بها ولم بيق إلى على هاتين الوظيفتين. الرفادة:

هي إطعام الحجاج في موسم الحج وقد فرض قصي على قريش خرجا تخرجه من أموالها وتدفعه إليه فيصنع به طعاما يقدمه للحجاج في أيام عرفات ومنى وقد تقدم ذكر ذلك، فجرى ذلك من أمره في الجاهلية حتى قيام الإسلام، ثم جرى في الإسلام إلى إلى يومنا هذا فهو الطعام الذي يصنعه السلطان كل عام بمنى للناس حتى بنقضي الحج(19). كان هذا العمل من قصي ينطوي على حكمة سياسية كبيرة، فإمداد الحاج بالطعام يدعوه إلى الإقبال على مكة لأن بعد

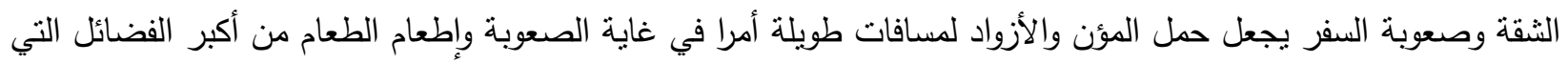




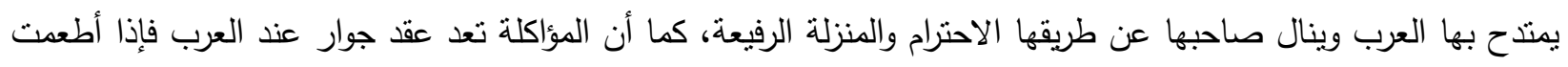
قريش القبائل في موسم الحج تتال احترامها وتقديرها. ولقد اعتبرت الرفادة إلى جانب السقاية حلفا قرشيا كبيرا مع كافة القبائل العربية. وظائف أخرى: ولقد استحدث ملأ قريش وظائف أخرى إلى جانب السدانة والسقاية والرفادة عندما تطلعت البطون القرشية للمشاركة في شؤون مكة، ومن أجل إرساء دعائم السلام وحرص الملأ على إرضاء العشائر استحدث عشر وظائف أخرى وأسندها للعشائر القرشية والوظائف هي: العمارة: وهي مراعاة الأدب والوقار في البيت الحرام، فلا يتكلم فيه بهجر ولا رفث ولا نرفع فيه الأصوات الحجابة: وهي قفل البيت الحرام وفتحه للزائرين المشورة: وهي أنهر لا يجتمعون على أمر حتى يعرضوه على صاحبها الأشناق: وهي الأموال الخاصة بالديات والمغارم والقيام على أدائها

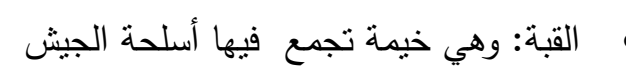
الأعنة: هي قيادة الخيل السفارة: وهي الاتصال بالقبائل الأخرى في المنافرات والمفاوضات الأيسار : وهي الأزلام التي يضرب بها عند هبل في جوف الكعبة الحكومة: هي الفصل في المنافرات والخصومات الأموال المحجرة: وهي الأموال المسماة للآلهة

على الرغم من أن مجلس الثيوخ (الملأ) كان وسيلة الحكم في مكة ويتولى شؤونها السياسية والاقتصادية والاجتماعية، فإنه لم يعتمد في تنظيم عمله على قانون مكتوب وإنما كان يصرف هذه الثؤون طبقا للعرف والعادة ومع ذلك لم يقض على حرية الأفراد فكل فرد كان يتمتع بحريته في إطار الثعور بحقوق الجماعة التي ينتمي إليها، وهو نفس النظام الذي كان سائدا في

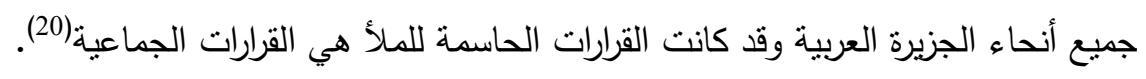
يرجع الفضل في قوة مكة إلى قوة زعمائها وقدرتهم على تكوين رأي عام وحل المنافسات الداخلية التي تتشأ بين العثائر على أساس المصلحة العامة والمحافظة على وحدة القبيلة التي كانت تتطلبها ظروفها باعتبارها قبيلة تجارية في بلد يعتمد في

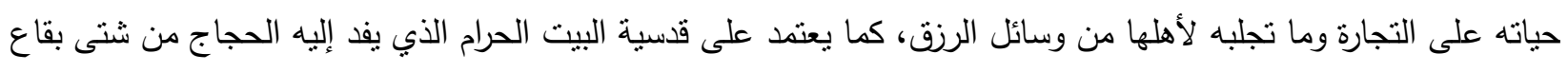

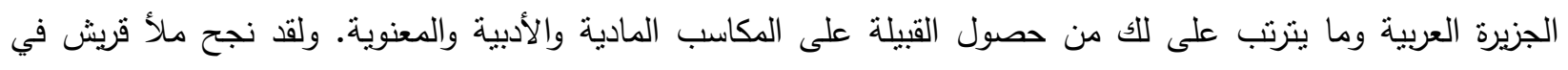

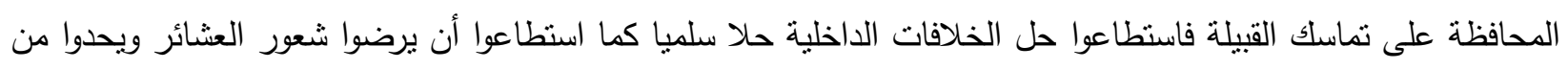
تتافسها على السلطة بأن توسعوا في قاعدة الحكم فأنشأوا الوظائف وأسندوا لكل عثبرة وظيفة تمارسها في نطاق القبيلة. 


\section{المبحث الثالث}

\section{القرشيون والحج والتجارة}

مما لاشثك فيه أن تجارة العرب وحجهم إلى مكة قبل الإسلام أمران متلازمان بحيث أنه لا يمكننا الحديث عن أحدهما دون الآخر، فالتجارة العربية قبل الإسلام حلقة هامة في تاريخ التطور البشري بما أوجدته من موروث ساهم في تشكيل الخريطة

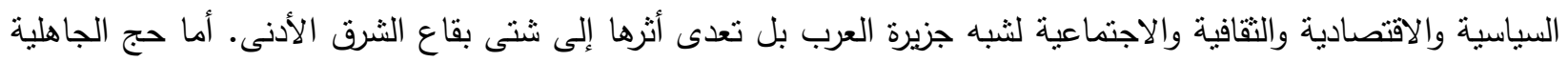
فلا نعرف منى بدأ على وجه التحديد، فالروايات في ذلك كثيرة ومتضاربة فقد ذكر دوزي(21) أن تاريخ مكة برتقي إلى أيام داؤود

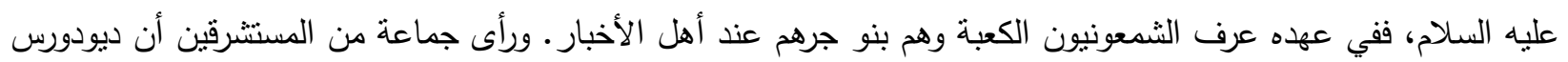

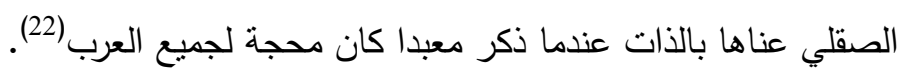
لاشك أن الصراع المرير الذي دار بين جرهم وخزاعة على ولاية البيت الحرام في القرن الرابع الميلادي على أرجح الأقوال كان مبعثه أن الولاية على البيت ندر المال الوفير من العشور والنذور والتجارة، وقد أسف بنو جرهم وحزنوا عندما أجلتهم خزاعة عن مكة فقال قائلهم: كأن لم يكن بين الحجون إلى الصفا أنيس ولم يسمر بمكة سامر بلى نحن كنا أهلها فأبادنا صروف الليالي والجدود العواثر

$$
\text { وكنا أولات البيت من بعد ثابت }
$$

نطوف بذاك البيت والخير ظاهر (23)

ويتضح مما أوردته المصادر أن مكانة مكة الدينية قد برزت بشكل واضح في آخر عهد الخزاعيين، أواخر القرن الثالث الميلادي، فكتب الإخباريين تظهر في القصص عن محاولات الحميربين غزو الكعبة لتحويل حج الناس إلى اليمن كفعل حسان

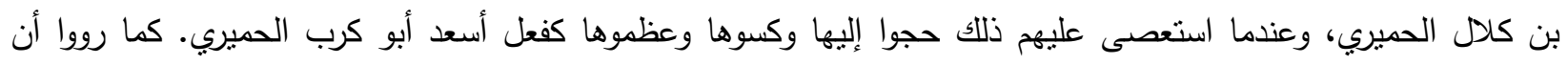
الاسكندر الأكبر وساسان بن بابك وغيرهم من مشاهير ذلك الزمان حجوا إلى مكة وكسوا الكعبة مما يدل على أن ذكر مكة قد وند

$$
\text { شاع خارج نطاق بلاد العرب(24). }
$$

لقد نجت قريش عندما آلت إليها الولاية على البيت وحكمت مكة أن تستقل الدين الوثني وشعائر الحج وتوظفها لخدمة مصالحها التجارية، فقد كان المكيون ينظمون مواكبا دينية يخرج فيها زعماء مكة يقودون الجمال تحمل القباب وبداخلها الأصنام يتبعها النساء وقد حلت الثُعور وضربن الدفوف والغرابيل وصدحن بأصوات الفرح والحماسة، يفعلون ذللك كلما خرجت لهم عير أو قدمت(25).فقد أصبح تعظيم البيت الحرام والقيام على أمر الحج محورا للحياة بمكة نظرا لما يجلبه من مصالح لا باهن 
عرف الحجازيون التجارة في وقت مبكر جدا ولعل جدب شبه الجزيرة العربية وشح مياهها بالإضافة إلى موقع الحجاز على العي

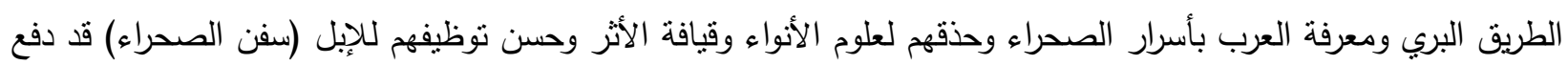

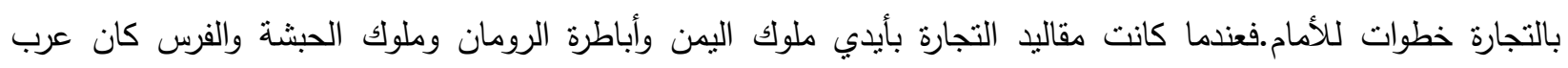

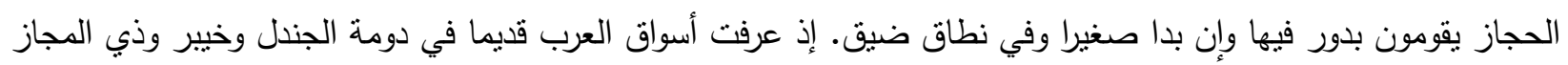

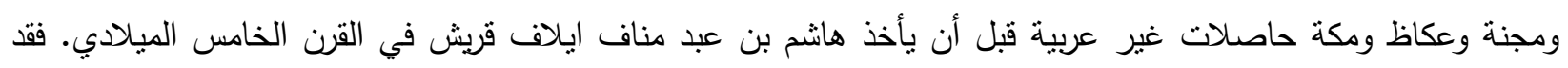
ذكر ابن حبيب أن قوافل قريش كانت تحمل إلى هذه الأسواق الزبيب والبرود اليمنية والأواني والثنياب (26).

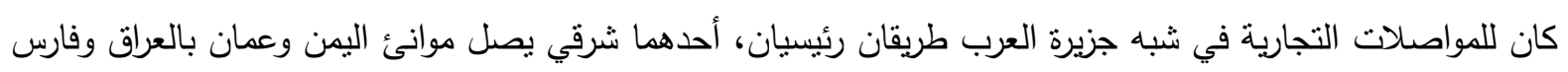

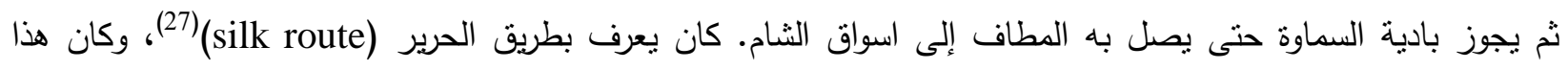

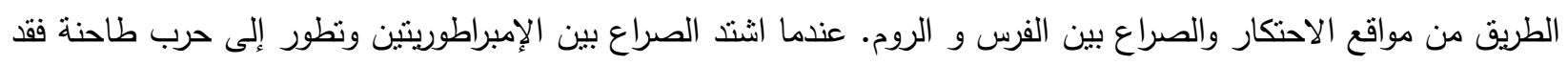

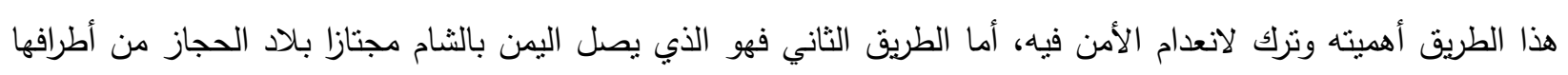

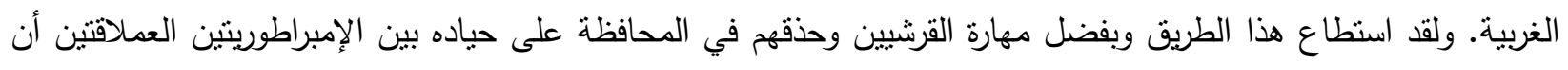

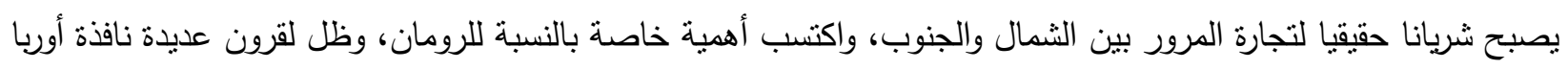

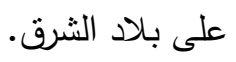
ولقد أفاضت المصادر الإسلامية في وصف هذا الطريق والطرق الموازية شرقا وغربا والطرق العرضية التي تتفرع منه

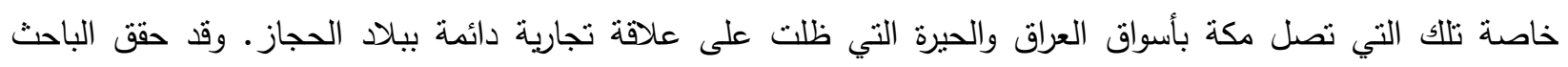

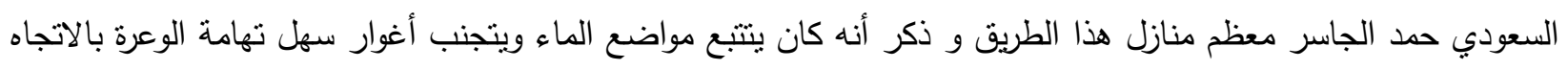

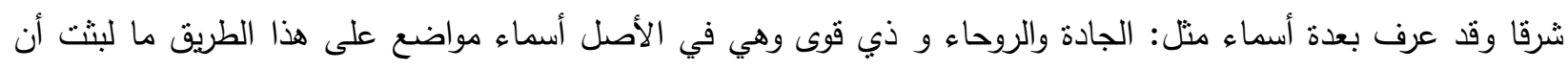
أصبحت علما عليه ونان. شغلت حرفة التجارة حيزا معتبرا في تفكير القرشيين وصارت محور اهتمامهم فالمتأمل لكتاب اله العزيز يجد فيه إثارات بعيدة

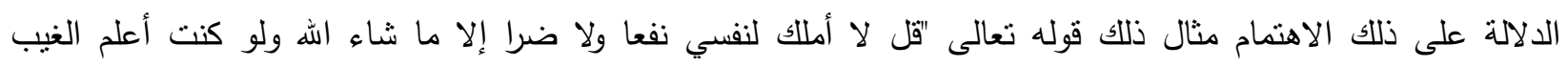

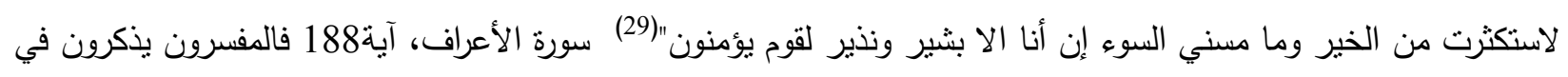

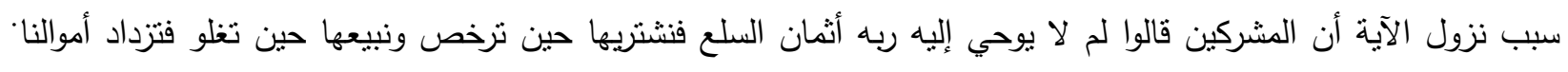

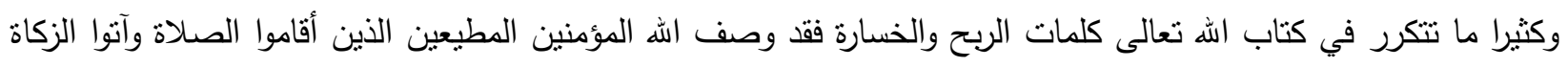

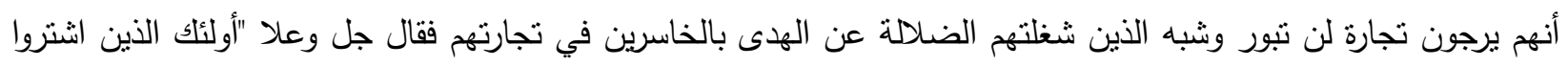

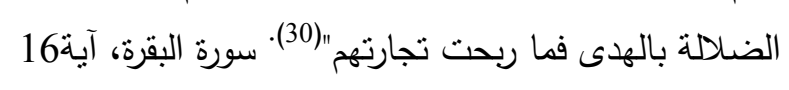

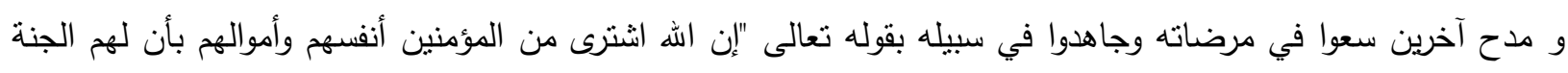

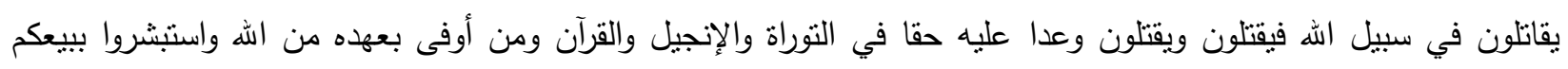

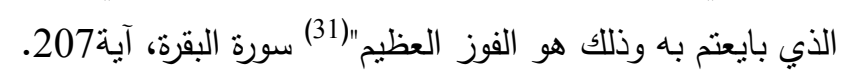
وقال تعالى في تأنيب الذين اشتخلوا بالتجارة عن الصلاة "وإذا رأوا تجارة أو لهوا انفضوا إليها وتركوك قائما"3207نسورة الجمعة، 
وذلك عندما انصرفوا لاستقبال القافلة القادمة من الثام وتركوا الرسول صلى الله عليه وسلم قائما يخطب من إعظامهم له وحبهر

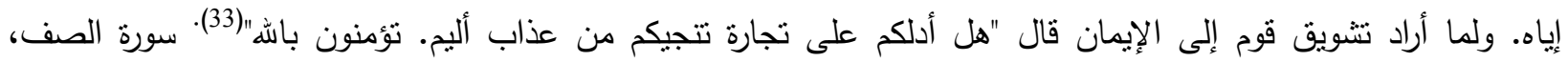

وكان للقرشيين اهتمام بما حولهم من الأقطار التي يتاجرون فيها ومراقبه لما يجري من أحداث وأنت تعرف ذلك من الحرب

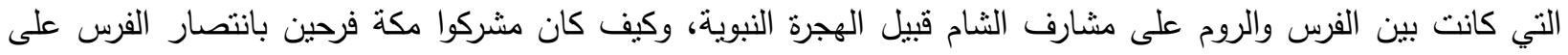

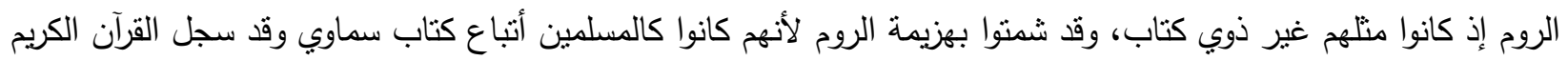

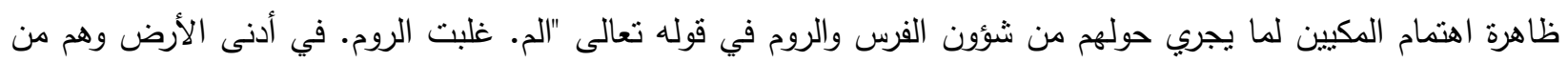

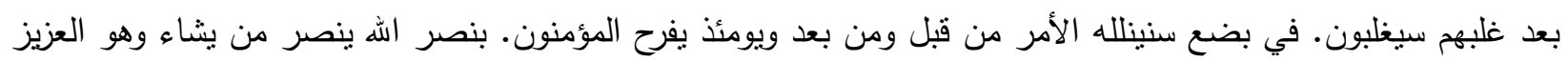

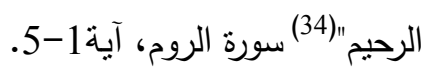

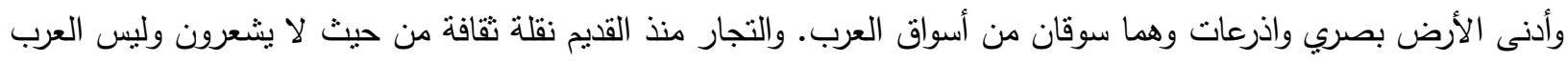
بدع في ذلك فقد أفادوا من اتجارهم واختلاطهم بالرومان والفرس وخضعوا للا يخضع إليه غيرهم من آثار الاختلاط، حتى إنا

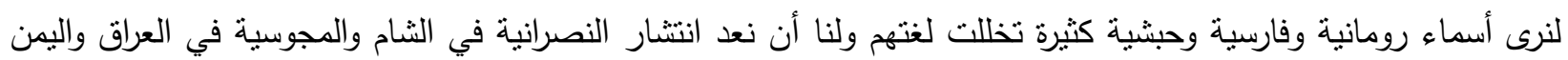
من آثار التجارة(35).

تكثر الأمثال التي تتعلق برحلات العرب التجارية وأحوالهم فيها مثل قولهم: عند الصباح يحمد القوم السرى - لا تدرك

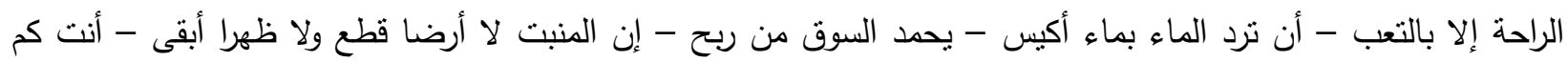
ستبضع التمر إلى هجر - لم يضع من مالك ما وعظلك. يذكر المشتظلون بدراسة اللغويات في أبحاثهم أن اللغة العربية تأثرت بالفارسية واللاتينية والحبشية والآرامية وقد كانت لغات التجارة في ذلك الزمان وقد لاحظ الباحثون ورود كلمات كثيرة من أصول شتى على اللغة العربية كانت في الأصل أسماء التهاء

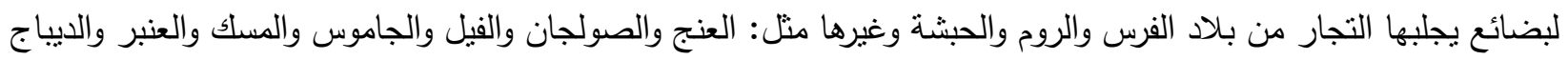
والإستبرق والإبريز والإقليم والإكسير والبيطار والدرهم والدينار والمنديل والفردوس ودكان.... الخ الخ الخدان

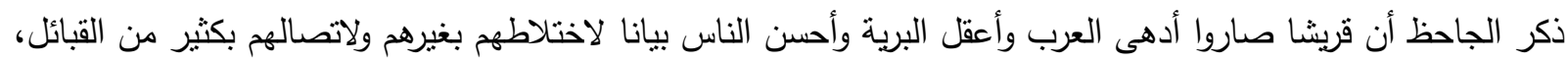

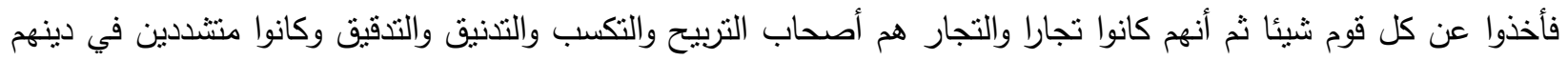

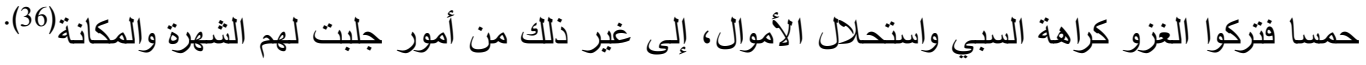




\section{الفصل الثاني \\ إستراتيجية قريش لصنع السلام}

المبحث الأول: إيلاف قريش الاخلي

أدركت قريش مبكرا بحكم جغرافية المكان والموقع أن ازدهارها لابد أن يعتمد على التجارة وأنه لا قوام للتجارة إذا لم يتوفر

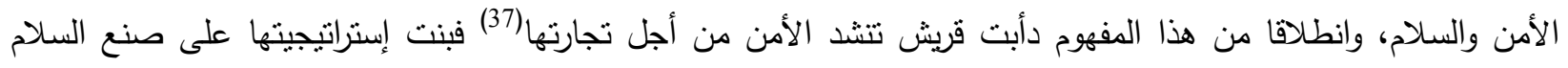
وحمايته بشتى الوسائل. فعلى الصعيد الداخلي حكمت مكة حكما جماعيا بواسطة ملأ قريش واشترك الأغنياء والفقراء في تسيير القوافل التجارية ثم أشركوا القبائل القاطنة على طول الطريق بين اليمن والثام في مشاريعهم التجارية. نم كل ذلك في إطار إستراتيجية قرشية شاملة لصنع وحفظ السلام فقد ظلت قريش منذ أن جمعها قصي بن كلاب بمكة في النصف الثاني من القرن الخامس الميلادي تعمل على نوطيد دعائم السلم بما يحقق مصالحها وقد شملت تلك الإستراتيجية إرضاء العشائر القرشية

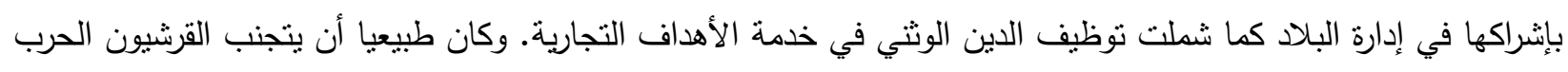
وما يقرب إليها لأن ذلك يتعارض مع إستراتيجينهم القائمة على نوسيع رقعة الأمن وقد بدا ذلك غريبا في أعين غير القرشيين فعابوهم واتهموهم بالجبن أحيانا (38). تتضح ملامح الإستراتيجية القرشية لاى إمعان النظر في المعاهدات والاتفاقيات والأحلاف التي عقدتها قريش في هذه الحقبة ومنها معاهدات الإيلاف المشهورة التي ورد ذكرها في القرآن الكريم في صورة الإيلاف، قال تعالى: "إإيلاف قريش. إيلافه رحلة الثتاء والصيف. فليعبدوا رب هذا البيت. الذي أطعمه من جوع وآمنهم من خوف"(39). ومن معاني الإيلاف

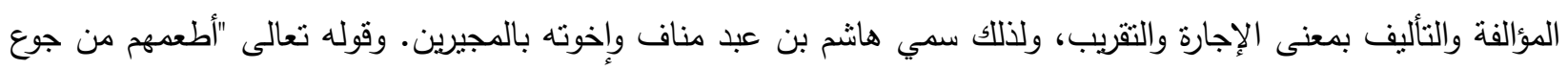
وآمنهم من خوف" يعني الضيق الذي كان فيه أهل مكة قبل أن يأخذ هاتشم لهم الإيلاف. والخوف الذي كانوا عليه ممن يمرون عليهم من الأعداء ومن ذلك قوله تعالى "واذكروا إذ أنتم قليل مستضعفون في الأرض تخافون أن يتخطفكم الناس فآواكم وأيدكم

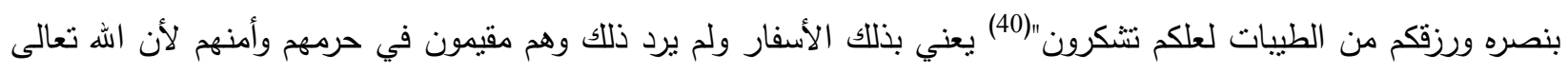
يقول "وإذ جعلنا البيت مثابة للناس وأمنا"(41).

لعب الإيلاف دورا بارزا بين عوامل قوة قريش ونهضتها فقد هيأ لمكة القوة المادية اللازمة. فظاهرة الإيلاف وليدة عوامل طبيعية وتاريخية، فمن الناحية الطبيعية كانت مكة منطقة صحراوية لا يمكن لأهلها الاعتماد على الزراعة في عيشهم، فلابد

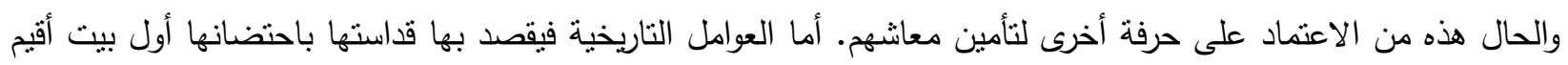
للناس وموقعها على طريق التجارة وما نشأ عن ذلك من تتظيمات جعلتها عرضة لأطماع القبائل المتجولة في المنطقة. كان من أهداف الإستراتيجية القرشية السلمية إثاعة الرضا بين العثائر والبطون القرشية ويتضح ذلك مما أورده الإخباريون في السبب المباشر لإيـاف قريش. تذكر المصادر ظاهرة اجتماعية سلبية ظهرت في مكة قبيل الإيلاف سببها الفقر والجوع عرفت باسم "الإعتفاد". وتعني أنه

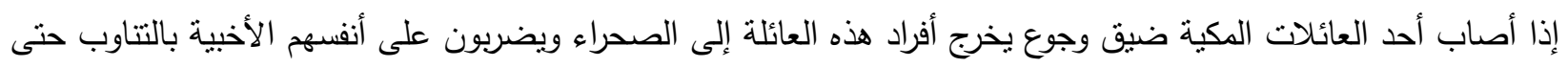
يموتوا دون أن يعلم بهم الناس. واستمرت هذه الظاهرة حتى زمن هاثت بن عبد مناف الذي استتكرها وبين عواقبها على إلى المجتمع المكي، وبين أن الاعتفاد لا يتتاسب مع شرف قريش وسمعتها الطيبة بين العرب، وطلب إلى قومه قطعها بالتوسيع على المحتاجين وإشراكهم بمشاريع التجارة حتى يصبح الفقير غنيا. وقال لهم في ما قال "إنكم قد أجدبنم جدبا تقلون فيه

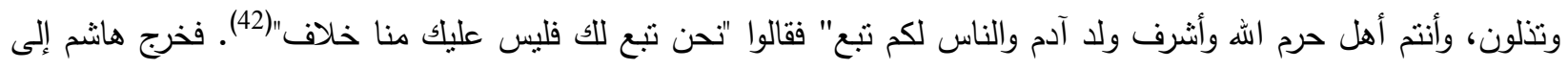


الثشام فأمر بخبز كثبر فخبز له فحمله في الغرائر على الإبل حتى وافى مكة فهشم ذلك الخبز وثرده ونحر الإبل ثم أمر الطهاة

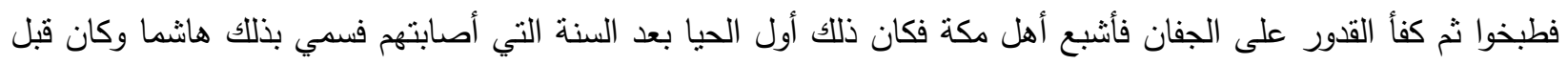

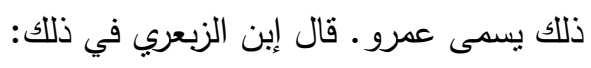

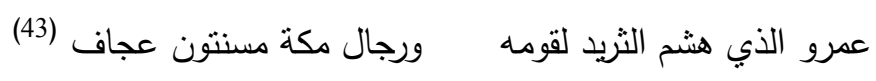

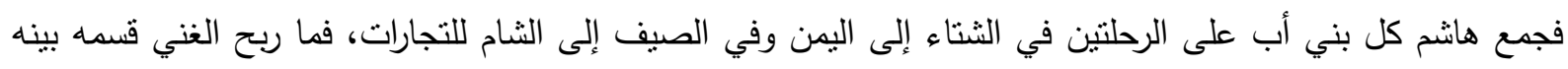

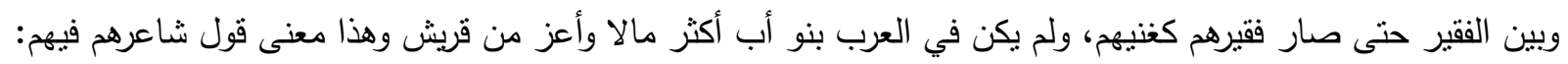

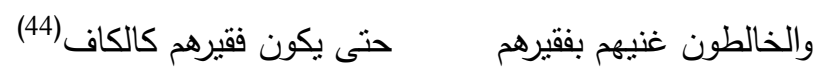

انتقلت أحوال قريش بفضل ما أثناعه هاثم من إيلاف بين عثائر قريش من طور إلى طور، فبعد أن كانت تجارتهم قاصرة

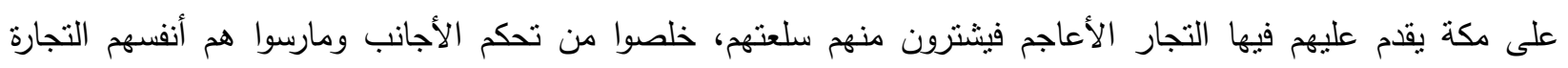

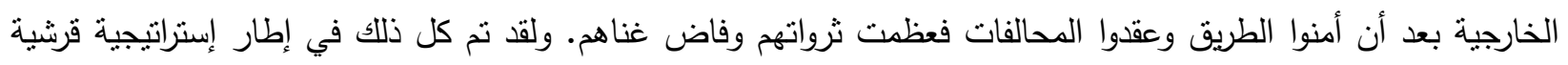

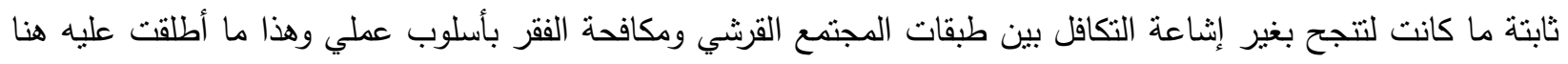
إيلاف قريش الداخلي. فايلاف قريش هنا يعني تراحمه وتواصلهم وتأليف قلوبهم بجعلهم جميعا شركاء في المستقبل. 


\section{المبحث الثاني \\ العصم والعهود الخارجية}

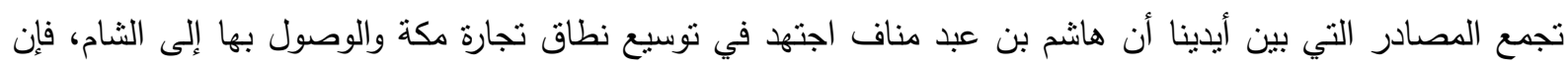

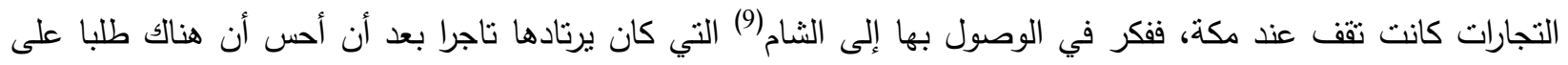

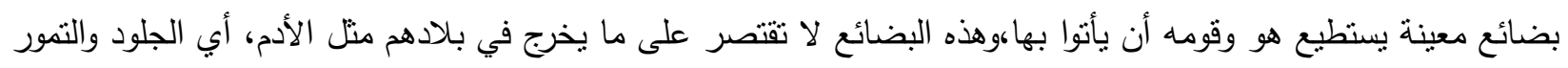

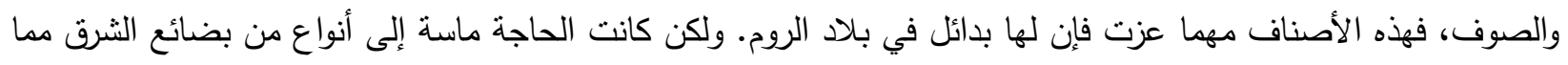

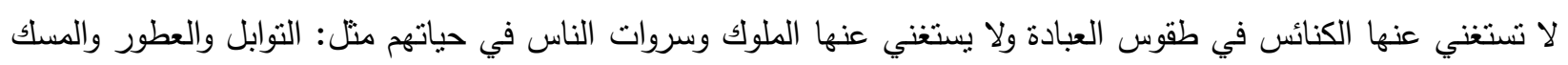

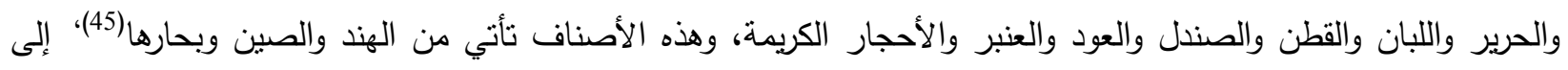

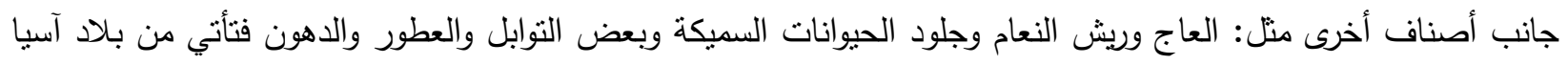
وأفريقيا.

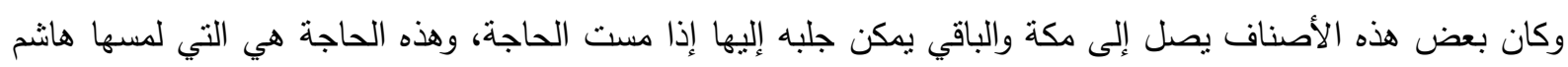

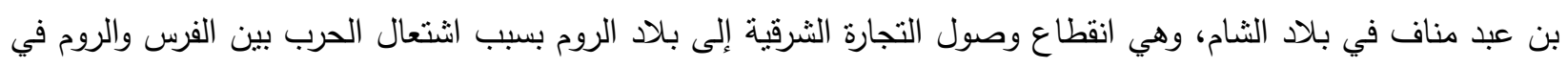

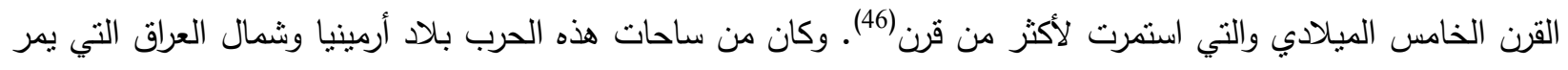

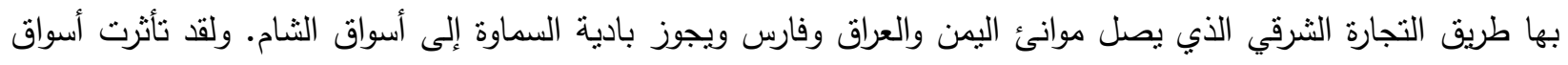

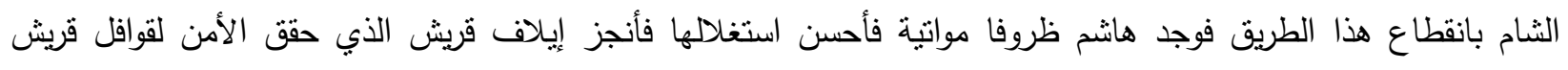
فخرجت من محيط التجارة المحلية إلى دائرة التجارة العالمية.

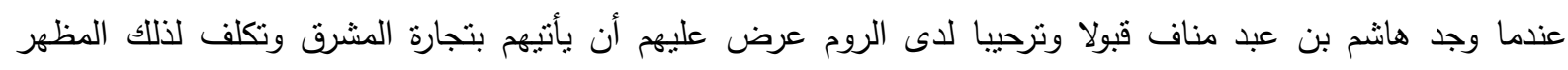

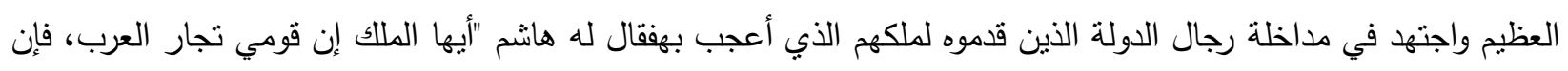

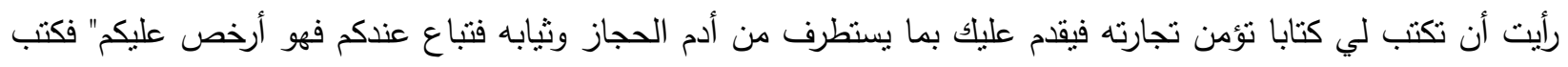

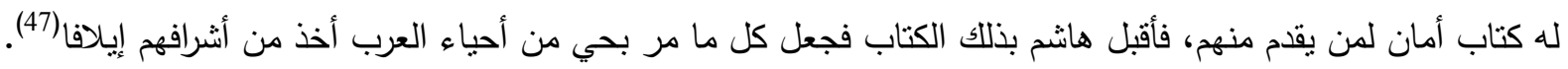

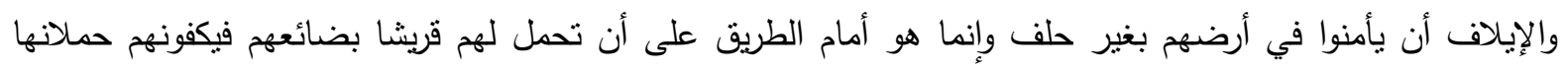

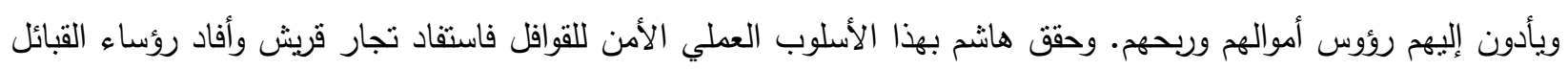

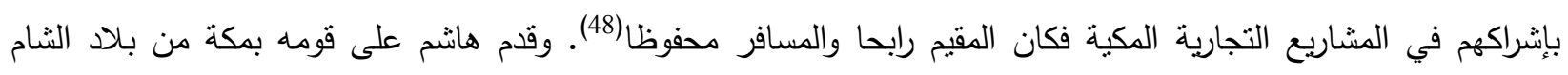

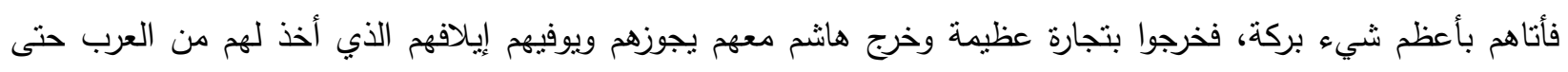

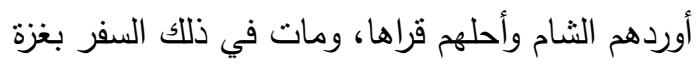

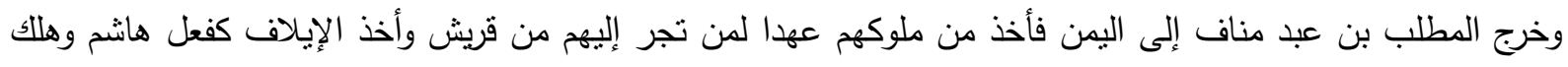

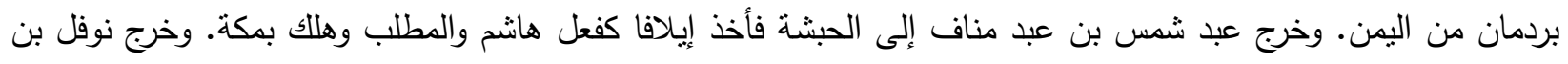

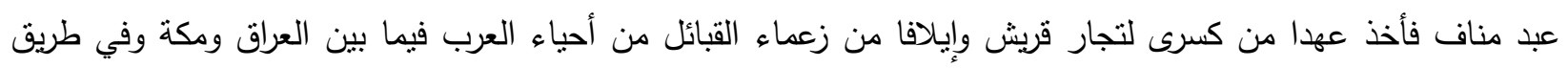

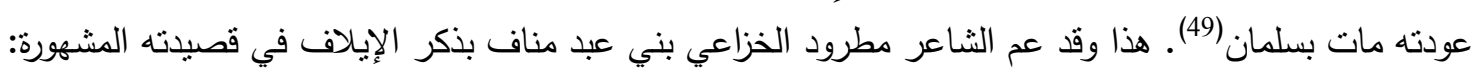
يا أيها الرجل المحول رحله

هلا حللت بآل عبد مناف تلف

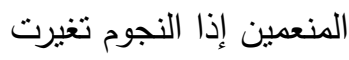


والظاعنين لرحلة الإيلاف

$$
\begin{aligned}
& \text { سفرين سنهما له ولقومه } \\
& \text { سفر الثتاء ورحلة الأصياف } \\
& \text { هبلتك أمك لو حلت لديهم } \\
& \text { ضمنوك من جوع ومن تطواف } \\
& \text { الآخذون العهُ من آفاقها } \\
& \text { والراحلون برحلة الإيلاف (50) }
\end{aligned}
$$

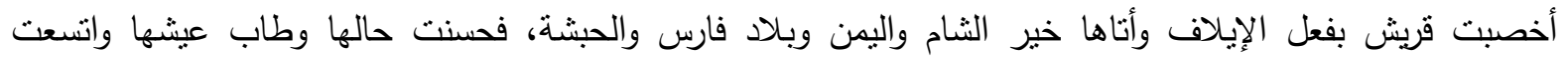

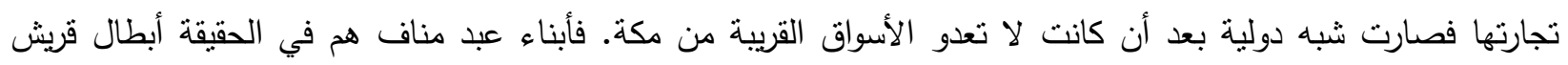

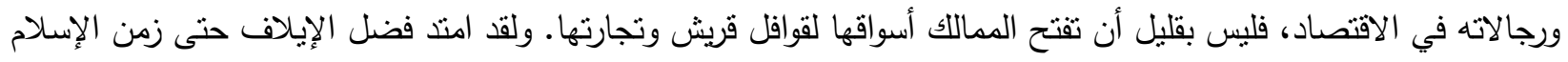

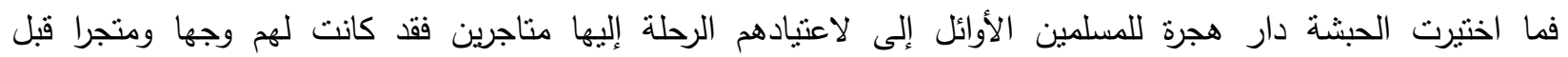

\section{المبحث الثالث \\ تأليف القبائل}

تأليف القبائل عملية ترويض كبيرة تتطلب جها وخبرة طويلة. فقريش التي خبرت طبائع الناس وبخاصة البدو من خلال

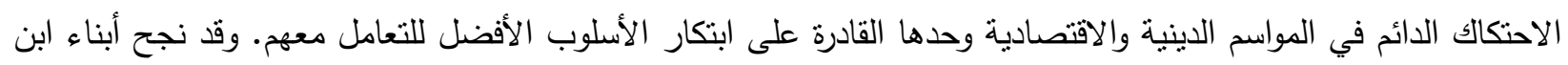

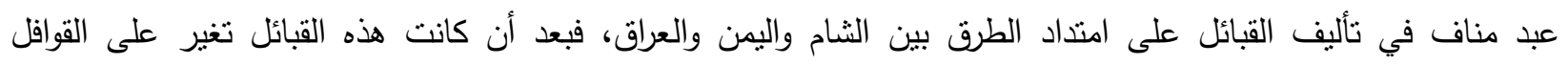

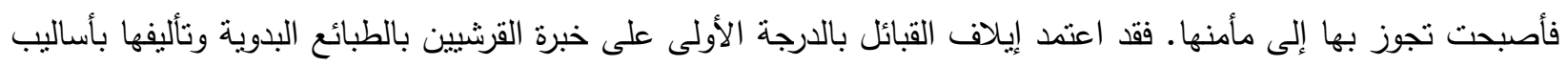

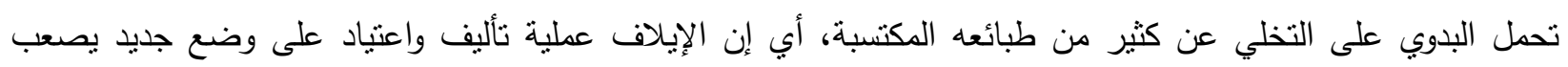

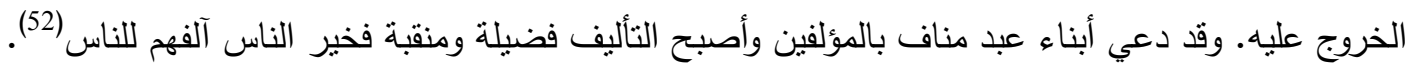

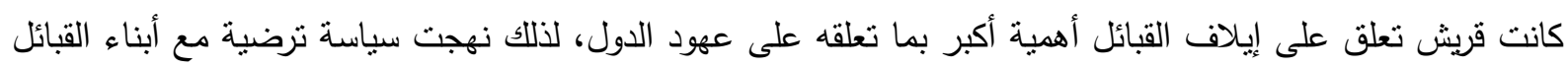

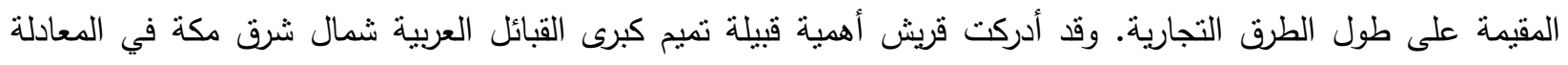

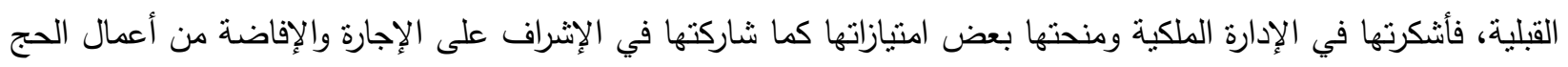

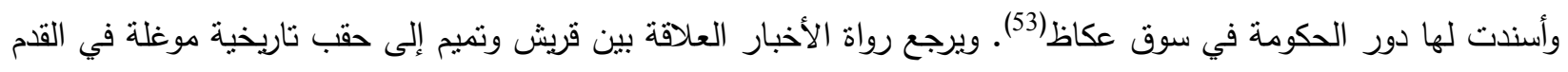

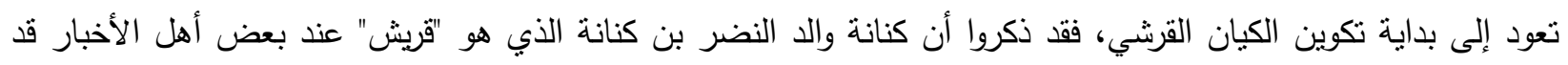

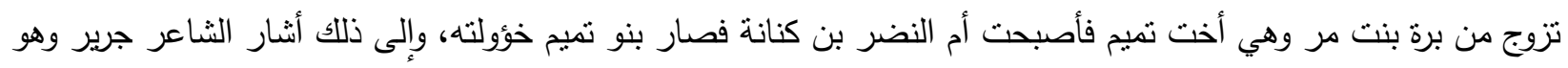
يمدح هثاما بن عبد الملك:

$$
\text { وما الأم التي ولدت قريثا }
$$

بمقرفة النجار ولا عقيم

$$
\text { وما قرم بأنجب من أبيكم }
$$

وما خال بأكرم من تميم(54) 
وكانت تميم على حلف مع قبيلة كلب أخطر القبائل العربية على تجار قريش لأن مواطنها انتشرت مابين أعالي الحجاز إلى بادية الثنام فلم تكن بطون كلب تتعرض لقوافل قريش ووقفوا مع قريش ضد الدعوة الإسلامية في بداية عهدها. كذلك خدم

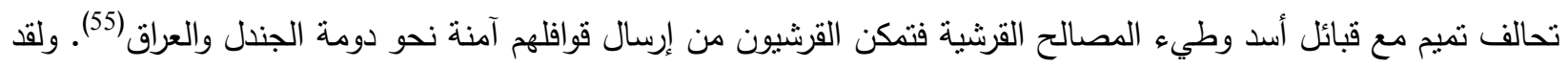
امتدت منازل تميم من وادي الرمة شرقا إلى وادي الباطن عند الطرف الثمالي الغربي من خليج العرب، فتحكمت بطرق المواصلات بين مكة والحيرة التي كانت تتولى فيها منصب الردافة وهو منصب ينوب فيه الرديف عن ملك الحيرة فأصبحت تميم شريكة إدارية في الحيرة ومكة(56). ارتبطت قريش بعلاقات ودية مع قبائل أشجع وسليم وبني أسد وأقامت بعض بطون غطفان وهوازن وسليم تحالفات مع أثراف قريش أساسها العلاقات الاقتصادية. وكانت تقيف على صلة دائمة بقريش إذ أن الطائف كانت مصيف ونيف رجالات مكة بملكون فيها البساتين والأطيان. وكانت لخزاعة في مر الظهران علاقات ودية مع قريش (57). أما قبيلة عذرة أحد بطون قضاعة صلات نسب بقريش منذ عهد قصي بن كلاب توطدت بالإيلاف. وكان لعذرة حلف مع قبيلة جهينة جعل الأخيرة تحترم المصالح

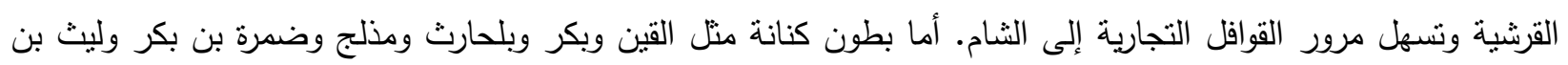
بكر فكانت تقطن حول مكة وتربطها بقريش صلات قوية بحكم الانتماء المشترك إلى كنانة. عرفت بعض بطون كنانة منل بني عامر بن لؤي وبني فهر بقريش الظواهر وكانت تغزو وتغير دفاعا عن قريش البطاح

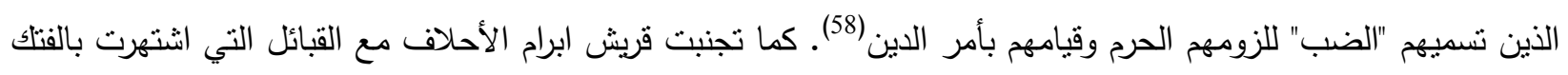

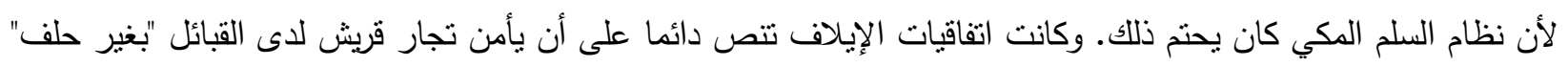
وذلك لخشية القرشيين أن يجر الحلف إلى حرب. فعندما طرد عبد الله بن جدعان -أحد سادات قريش المعدودين - إبلا لأحد سادات قبيلة هوازن وتوترت العلاقات بين هوازن وقريش;ائترت قريش بقتله أو تسليمه لئلا يجر عليهم الجرائر وبطلبون بسببه

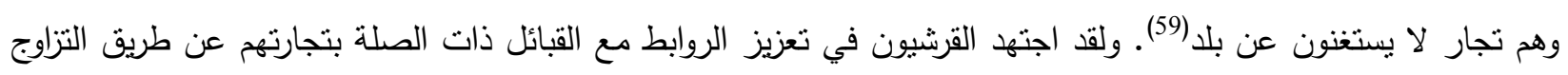
والمصاهرة. وتزخر كتب الأنساب بالإشارات لهذه السياسة القرشية.

\section{الفصل الثالث}

\section{إستراتيجية قريش لحماية السلام}

رأينا في الفصلين السابقين كيف أن التجارة أصبحت قوام الحياة في الحجاز وكيف أن القرشيين برعوا فيها حتى أصبحوا وسطاءها العالميين وكيف أن صنع السلام وحمايته صار هاجسهم الأوحد. ولقد بذلت قريش جهودا موفقة في صنع السلام عبر إدارتها الجماعية لشئونها عن طريق الملأ والهياكل الإدارية الأخرى، وإيلاف قريش وما تضمنه من تكافل اجتماعي داخل

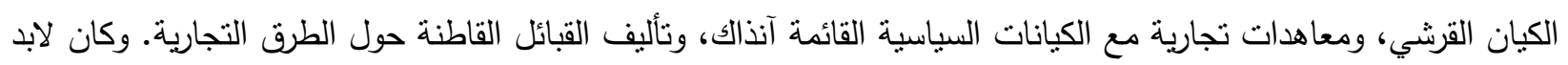

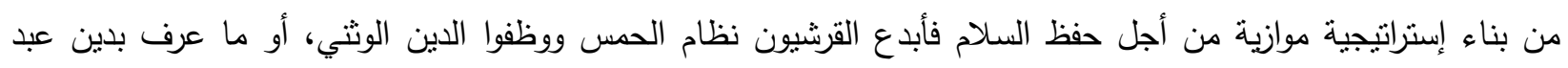

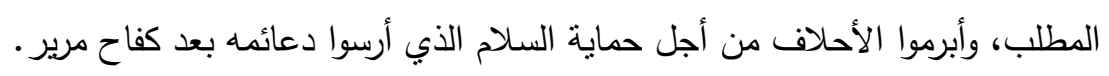




\section{المبحث الأول}

\section{نظـام الحمس}

صارت قريش قبيلة مستقرة واتخذت التجارة لها رزقا وعاثت على الأرباح التي تجنيها من مجيء الأعراب إليها في مواسم

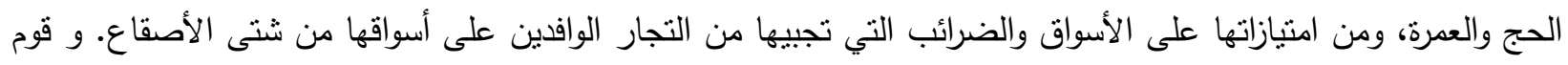

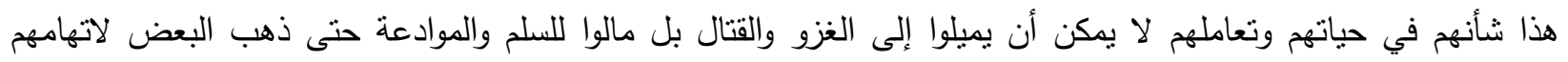

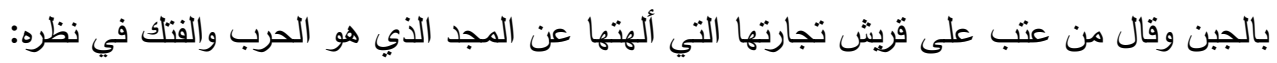

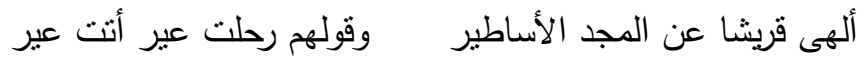

لكن هذا الثاعر لم يفطن لجوهر الأمر كما فعل الجاحظ الذي قال "إن قريشا دانت بالتحمس والتثتدد في الدين وتركوا الغزو

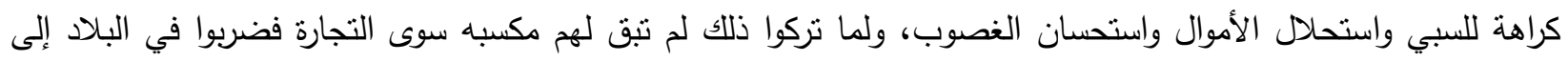

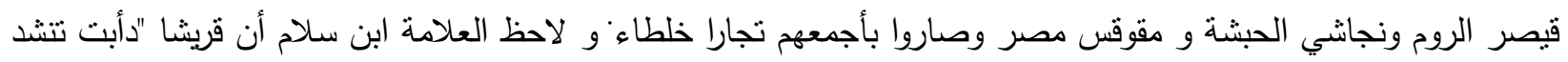

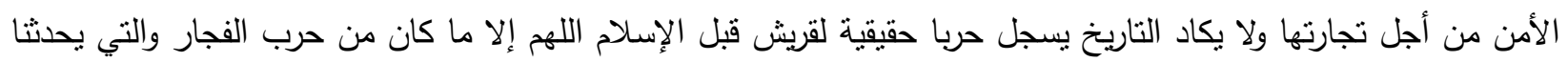

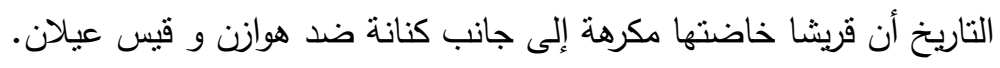

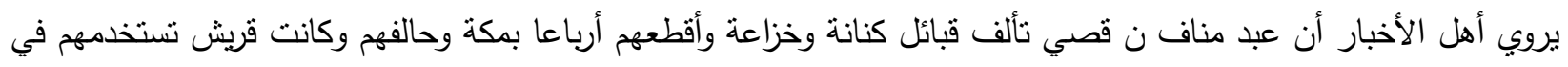

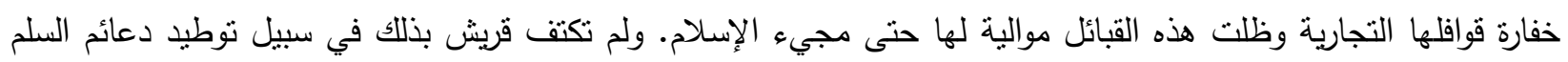

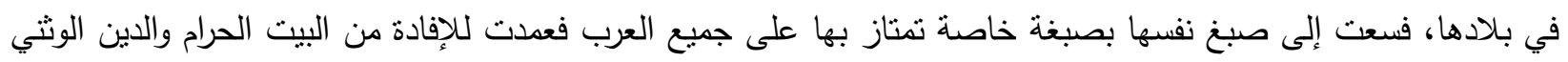

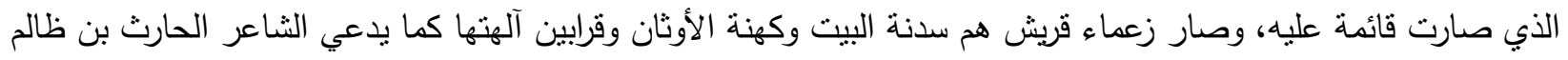

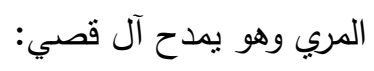

$$
\text { وان تعصب بهم نسبي فمنهم قرابين الإله بنو قصي }
$$

عرف هذا النظام القرشي بنظام الحمس أي المتثددين في الدين و هو يعد ضمن التنظيمات القرشية التي تهدف لتأمين تجارة

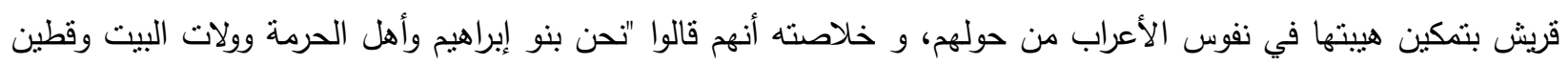

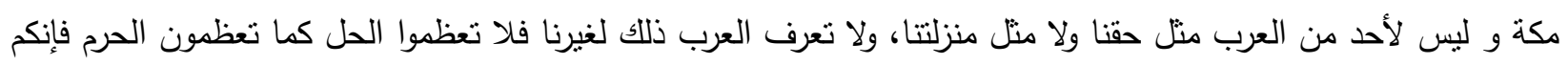

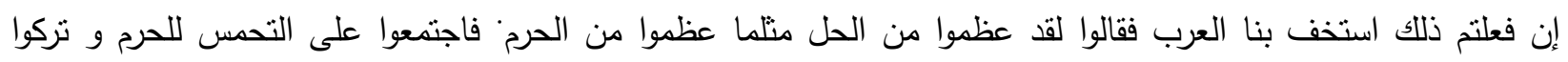

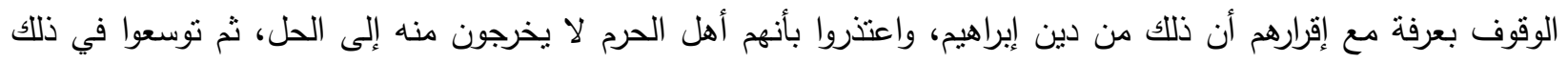

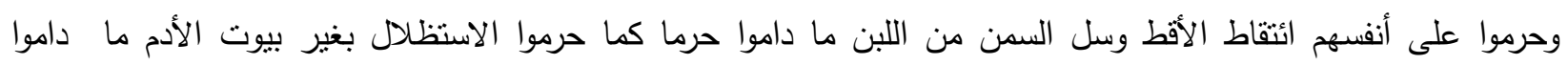

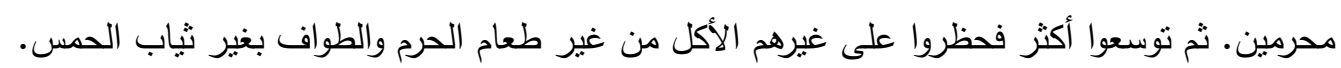

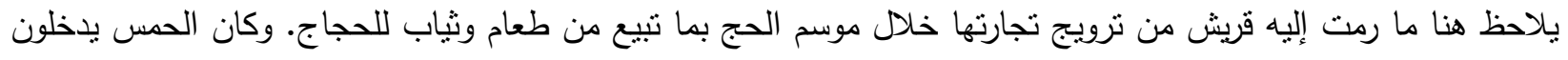

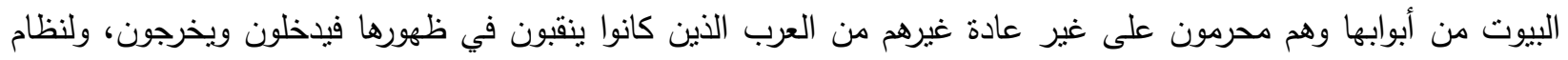

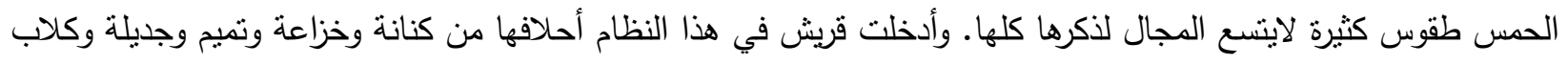

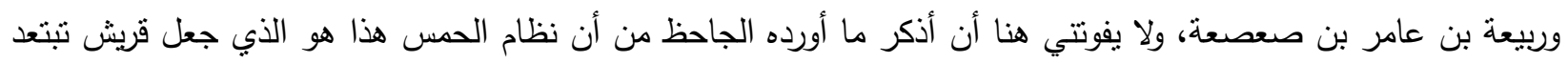


عن مزاولة العادات والطبائع الجاهلية التي سادت عند غيرهم منل الوأد والأنكحة الفاسدة والفتلك والاغتصاب ولقد كان لفتل حملة أبرهة الحبشية عام الفيل وهو عام 570 ميلادي على أرجح الأقوال أثرا إيجابيا في تثبيت أركان هذا النظام. ارتبطت قريش عن طريق نظام الحمس بمعاهدات صداقة وعدم اعتداء مع قبائل جهينة ومزينة وغطفان وأثجع وسليم وبني

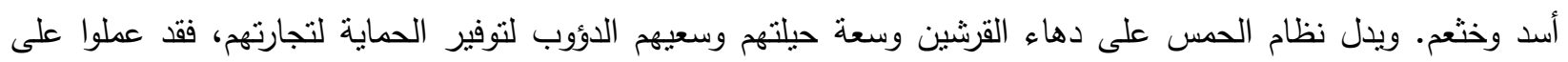
إحاطة أنفسه بهالة من التقديس مستغلين في ذلك بيت الله الحرام ومكانته عند العرب وكانوا يشترطون على من يصهر إليهم الإقامة معهم والدخول في نظام الحمس ليضمنوا عدم انتهاك منطقة الحرم وحياد مكة. لقد ثبت نجاح ثلاك السياسة القرشية بشواهد تاريخية كثيرة منها على سبيل المثال تصدي قبائل خثعم وهم من أفتلك قبائل العرب

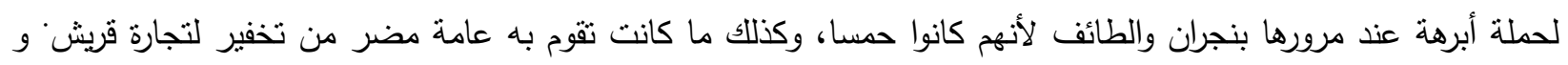

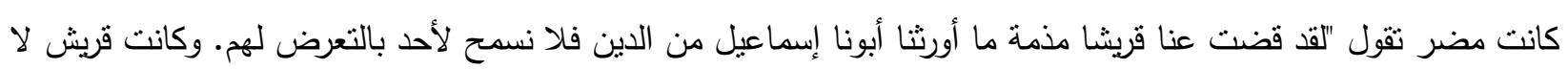
تتخفر عندما تجتاز أراضي كلب وطي من قبائل ربيعة لأنهم حلفاء تميم وبني أسد وعامتهم من الحمس ويمكن أن نستنل على ونى

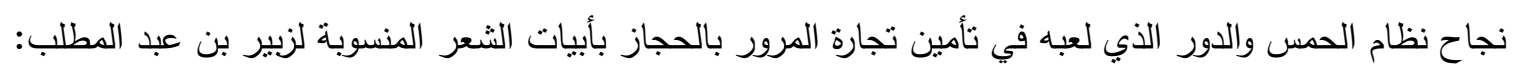

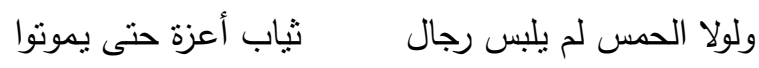

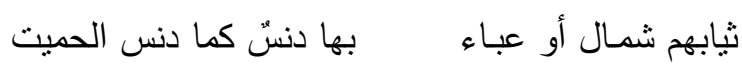

رمت قريش بنظام الحمس كذلك إلى إعلاء شأن الأشهر الحرم التي كانت تتحول فيها مكة وما حولها إلى سوق عالمي يؤمه التجار من شتى أنحاء المعدورة مما يستلزم الأمن والاستقرار الذي لم تأل قريش جهدا في سبيل توفيره والمحافظة عليه. ولكنهم كانوا يتدخلون في ترتيب الأشهر الحرم بالنسئ أي التأجيل وفقا لمقتضيات أحوالهم، وكان النسأة من بني كنانة فكانوا إذا

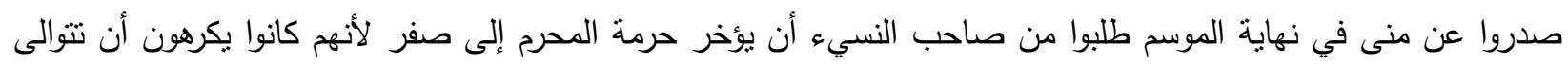
عليهح ثلاثة أثنهر حرم فيستجيب لهم فيحل هم "محرما" ويحرم عليهم " صفرا"وهو تلاعب بالدين واستغلاله لخدمة مصالحهم

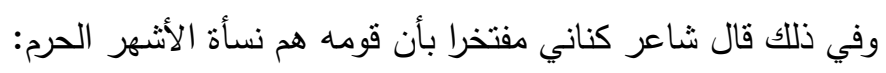

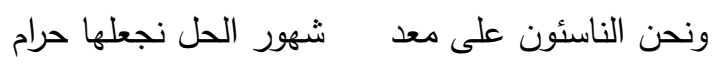

ذم القرآن الكريم التلاعب بحرمة الأشهر الحرم فقال تعالى "إنما النسيء زيادة في الكفر يضل به الذين كفروا يحلونه عاما ويحرمونه عاما ليواطئوا به عدة ما حرم الله فيحلو ما حرم اله “ وعلى هامش نظام الحمس نشأت بعض العادات الاجتماعية

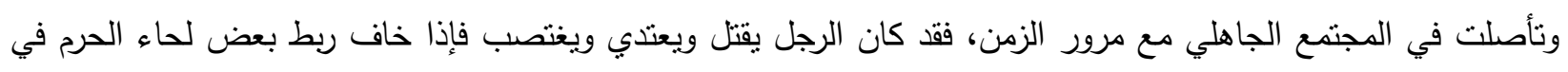

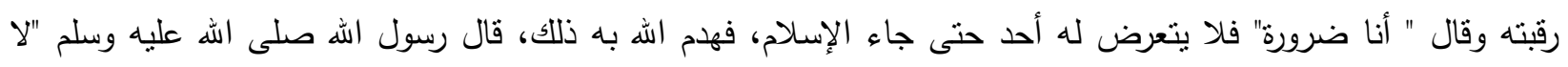

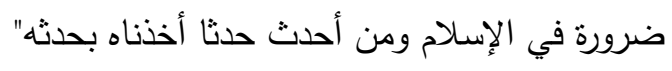




\section{المبحث الثاني \\ دين عبد المطلب}

لكي تكتمل صورة الكيان القرثي وهو في أوجه قبل الإسلام، لابد أن نلم بطرف من أعمال عبد المطلب بن عبد مناف الذي الذي

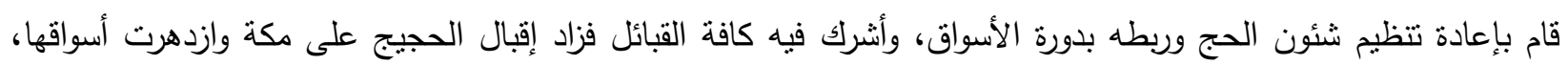

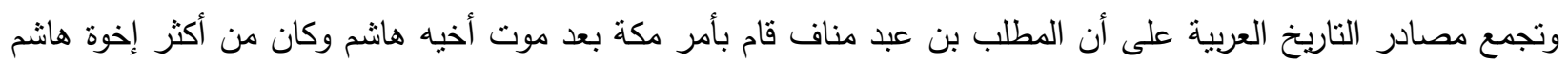

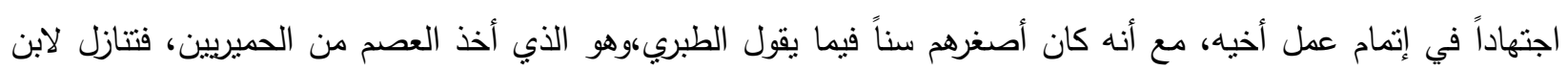

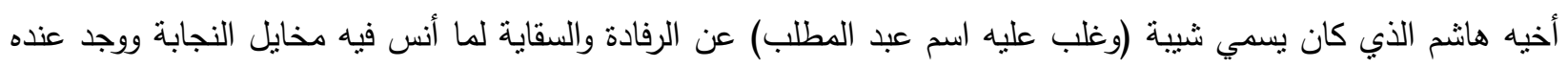

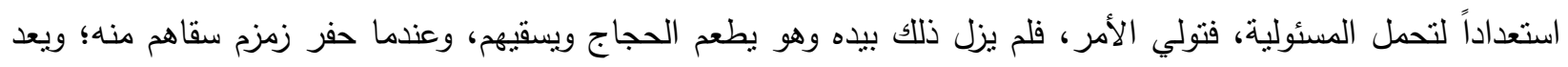

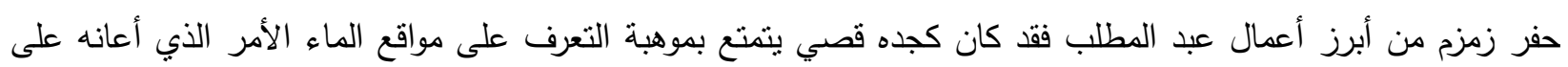

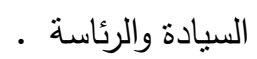
نظر عبد المطلب بعد أن صارت له الرفادة والسقاية والندوة بأمر الكعبة فوجد أنها محج العرب، يجتمعون فيها للحج والتجارة

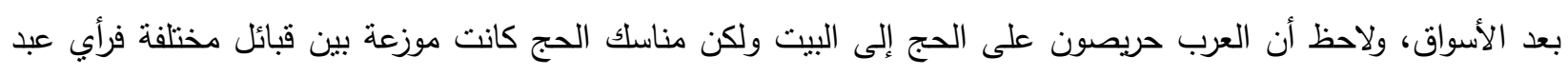

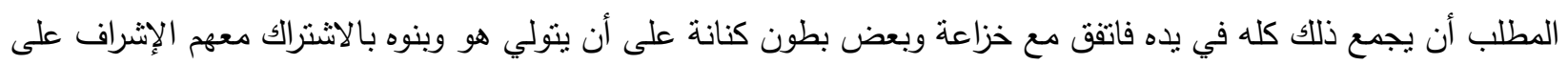

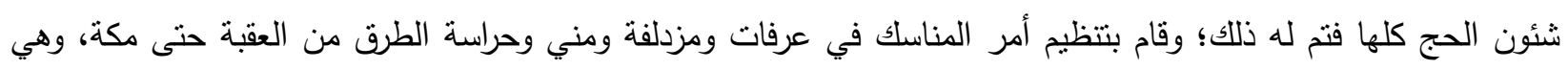

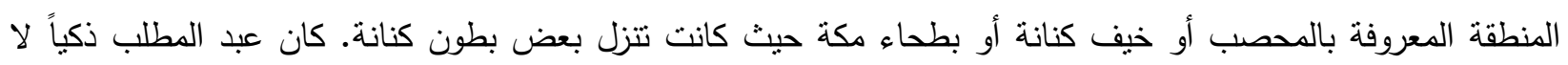

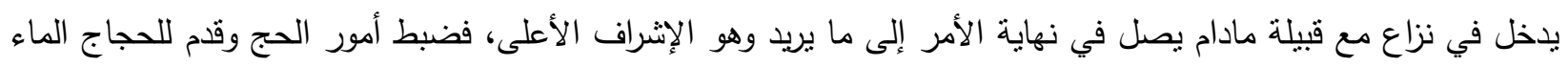

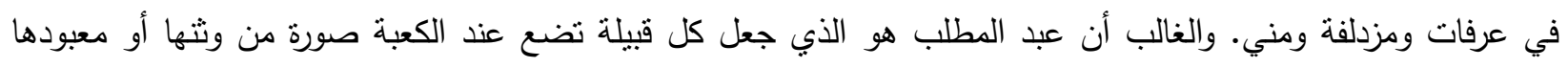

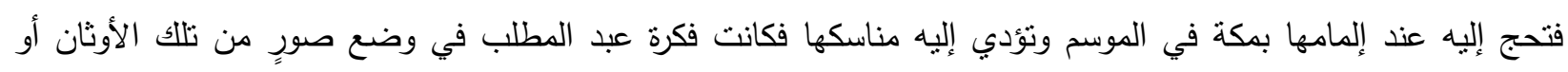
رموزٍ لها حول الكعبة فكرة صائبة.

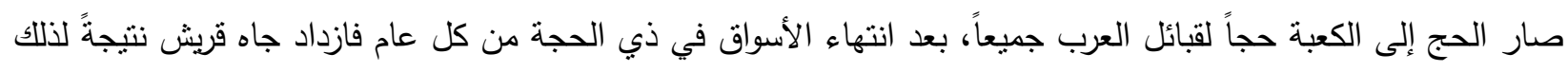

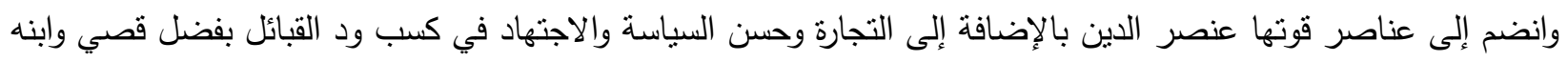

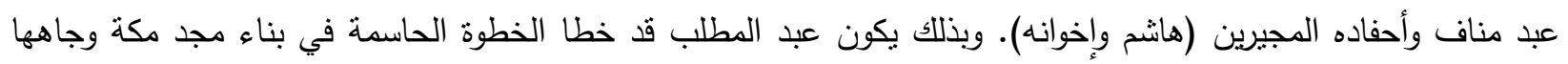

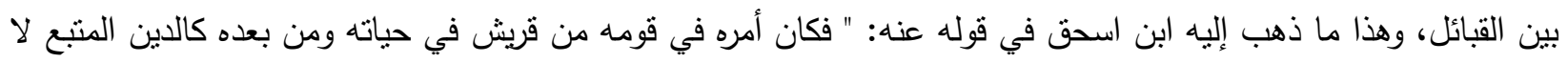
يُعمل بغيره

من الأحداث الجسام التي وقعت بمكة على عهر عبد المطلب غزو أبرهة الحبشي للحجاز عازماً هدم الكعبة، واجتاح بالفعل

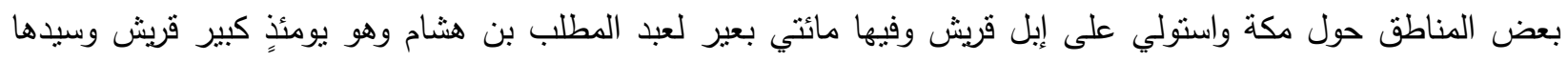

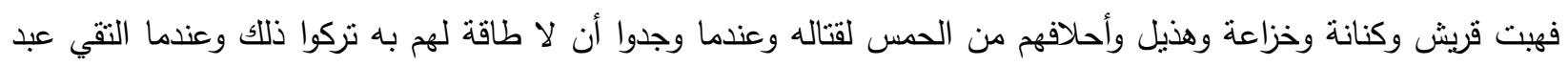

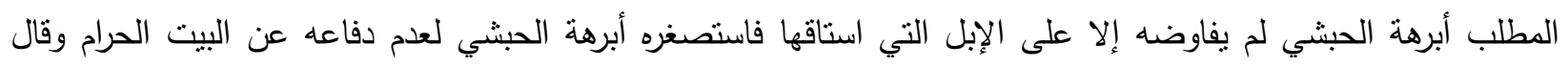

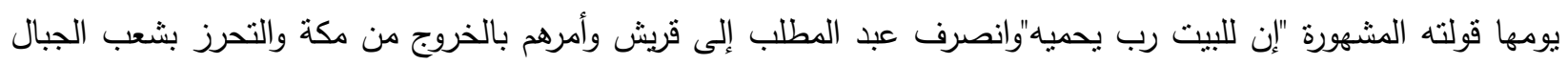

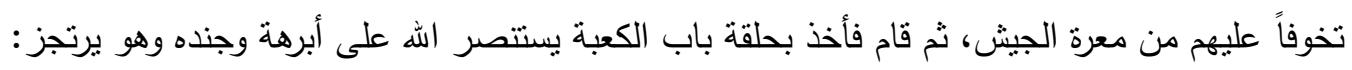




$$
\begin{aligned}
& \text { لا هم إن المرء يمنع رحله فامنع رحـالك }
\end{aligned}
$$

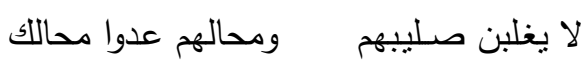

أهلك اله جيش أبرهة بالطير الأبابيل التي ترمي بحجارة من سجيل فنجت مكة وحرمها من التخريب على يد أبرهة بفضل الله

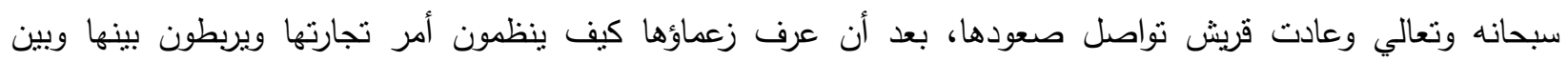

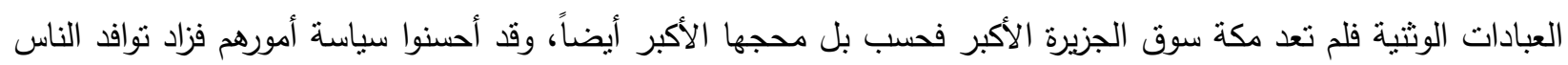

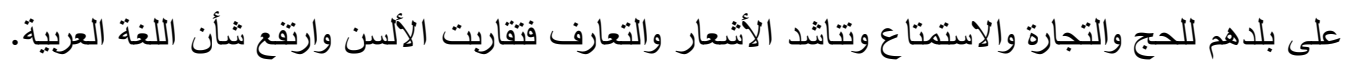

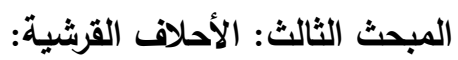

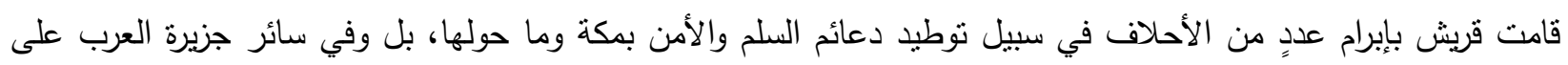

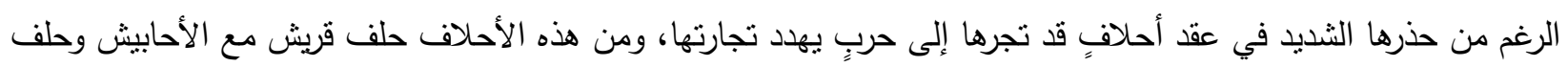

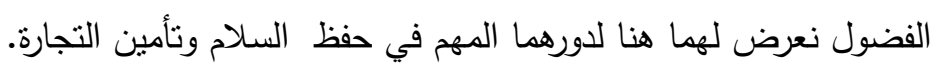

\section{حلف الأحابيش:}

يورد البعقبي خبراً طويلاً مفاده أن عبد مناف صار رئيساً لككة بعد أبيه قصي واجتهد في إكمال عمله السياسي بتأليف القبائل

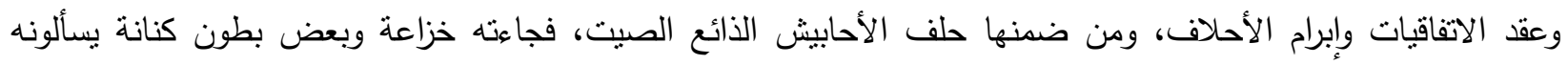

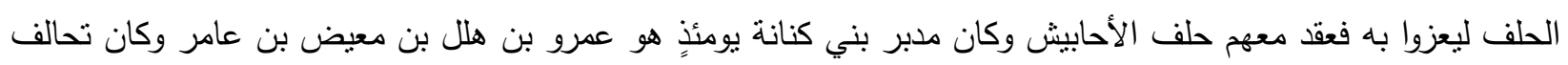

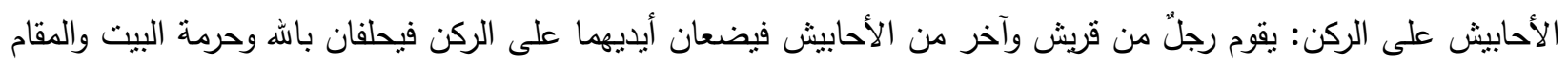

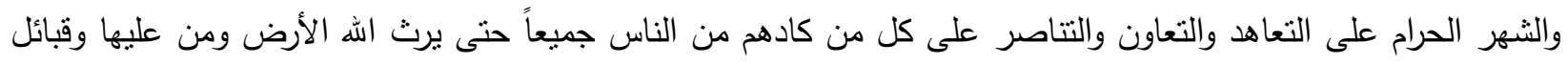

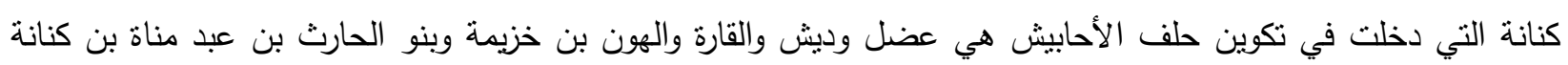

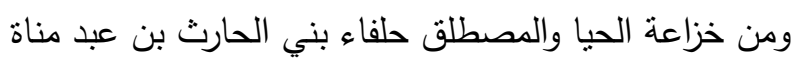

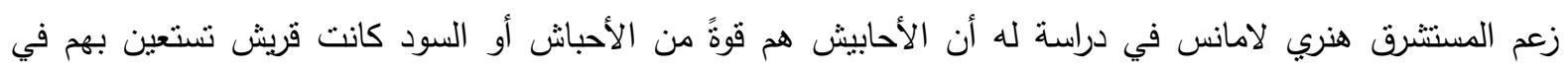

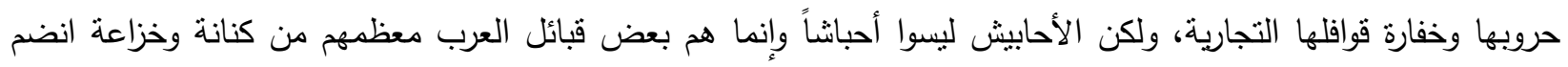

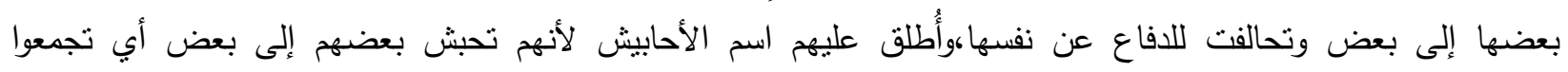

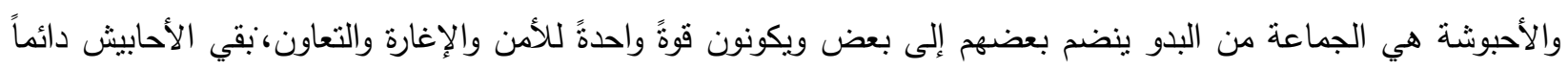

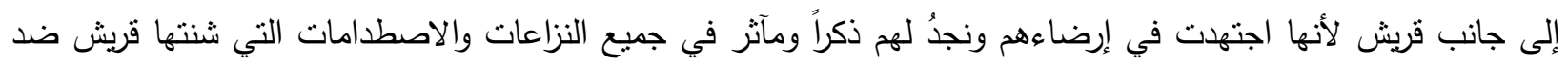

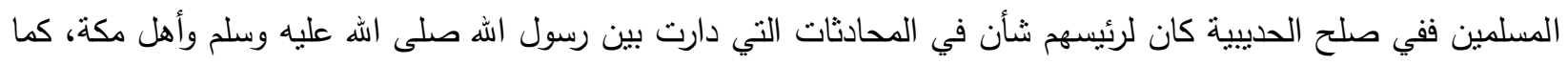

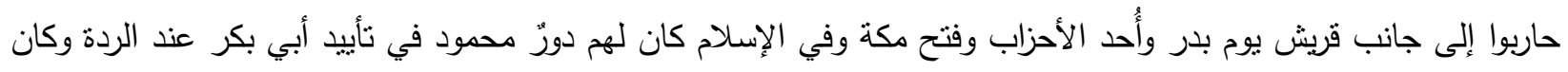

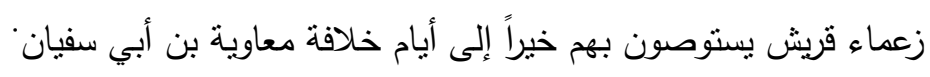

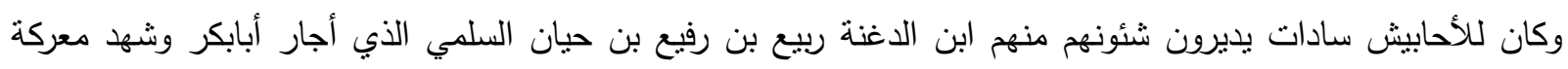

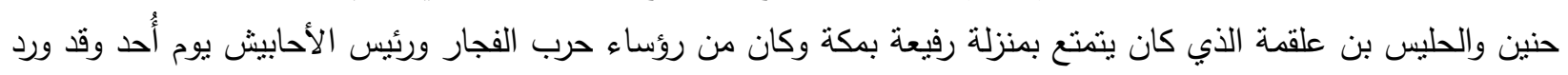

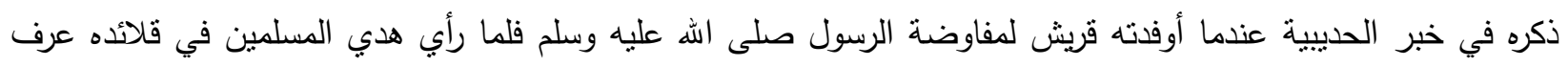

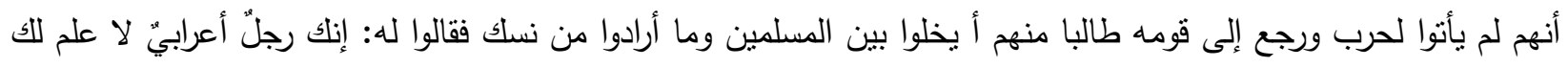

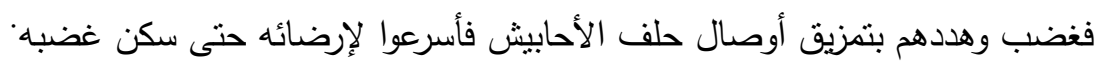


يعتبر حلف الأحابيش إنجازا قرشيا مهما خدم مصالح قريش التجارية وتوطلت به دعائم السلم المكي وقويت به شوكة

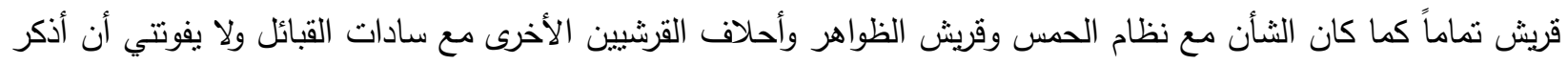

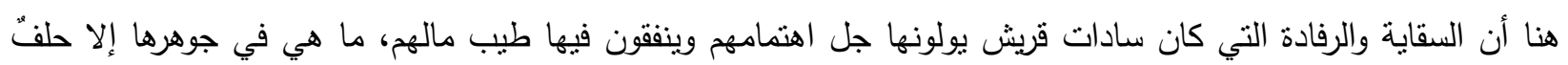
كبير يتجدد كل عام مع كافة قبائل العرب.

حلف الفضول:

حلف الفضول من الأحلاف المهمة التي يذكرها أهل السير والأخبار في ناريخ مكة وقد عقد في السنة التي وقع فيها الفجار الذي حضره الرسول صلى الله عليه وسلم وهو ابن عشرين سنة، وعليه يكون قد عقد سنة 590 ميلادي؛ ويذكر أن الذي دعا إليه هو الزبير بن عبد المطلب وندب إليه أهل الفضل من قريش فثهده بنو هاشم وبنو المطلب وبنو أسد وبنو زهرة وبنو ثيم في دار عبد الله بن جدعان. ويذكر أنهم تعاهدوا على أن يكونوا مع المظلوم بمكة حتى يؤدي إليه حقه وفي التأسي في في في

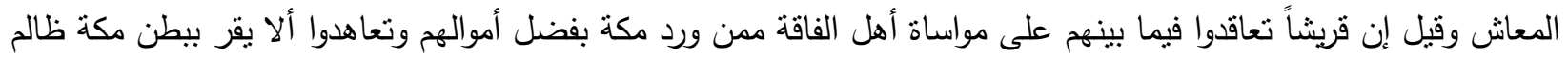

كما قال الثاعر:

$$
\begin{aligned}
& \text { إن الفضول تحالفوا وتعاقدوا ألا يقر ببطن مكة ظالمُ } \\
& \text { أمرٌ عليه تعاهدوا وتواتقوا فالجار والمعتر فيهر سالم }
\end{aligned}
$$

ذكر أهل الأخبار أن الغاية من الحلف هي إنصاف المظلومين من الضعفاء والمساكين من أهل مكة ومن لا يجد له عوناً يحميه ويدافع عن حقوقه من الغرباء الوافدين على مكة من حجاج وتجار، فلم تكن مكة تخلو من أناس بطرين يستهينون

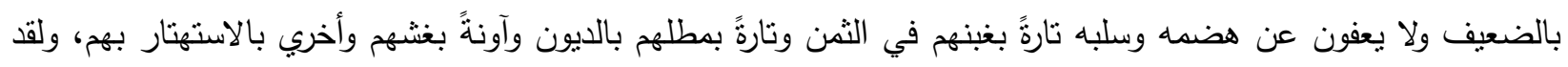

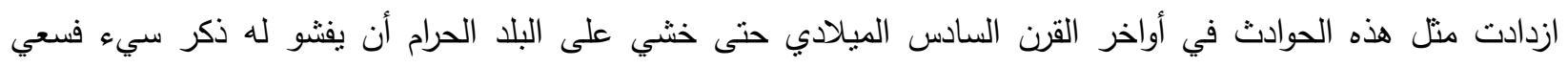
الأشراف بعضهم إلى بعض وعقدوا حلف الفضول ونصبوا أنفسهم لحمايته. ويروون أن السبب المباشر لعقد هذا الحلف أن رجلاً من أهل اليمن باع سلعة إلى أحد كبار تجار قريش فظلمه بالثن فأوفي على جبل أبي قبيس رافعاً عقيرته وقريش في أنديتها فذكر ظلامته في شعرٍ له:

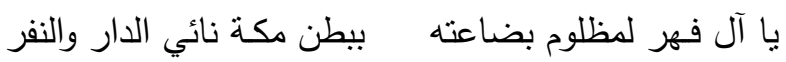

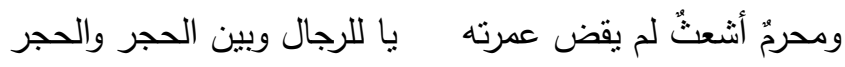

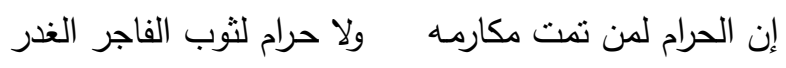

فاهتم للأمر أهل الفضل من قريش وعلى رأسهم الزبير بن عبد المطلب الذي لم يهدأ له بال حتى رُدت ظلامة المظلوم ونشط بعد ذلك في عقد حلف الفضول على الصورة التي تقدم وصفها. وقد شهد هذا الحلف رسول الله صلى الله عليه وسلم وهو فتي،

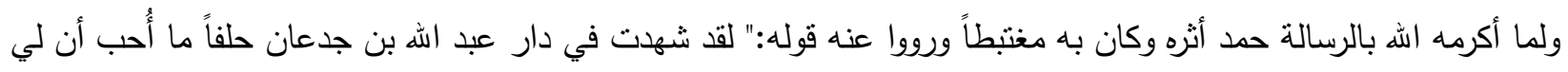

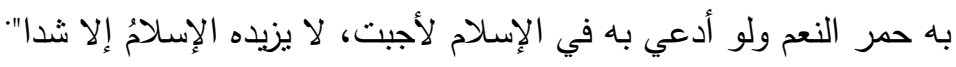

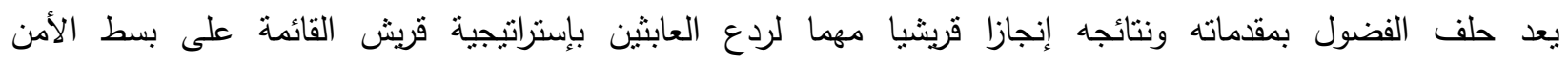
وحراسته.وتبرز أهميته في أنه حفظ سمعة قريش وصان ازدهار أسواق مكة وأسبخ عليها ثوباً من الإنصاف والأمن وحماية الضعيف بعد أن كاد عقد الأمن فيها ينفرط وكادت حوادث الاعتداء على حقوق الضعفاء أن نزعزع نقة الأعراب وتجار 
النواحي في أسواق مكة.وقد نظمت قريش أمر حلف الفضول فاهتمت به كل الاهتمام ولم ينقطع أثره في الإسلام.فيروي ابن

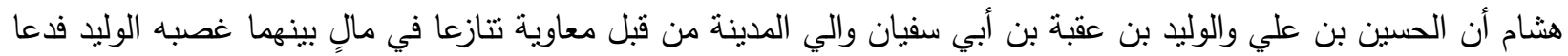

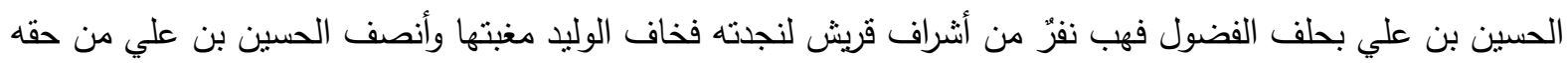
وهكذا كان حلف الفضول إضافة هامة لنظام السلم المكي تدل على بعد نظر القرشيين ومدي تمسكهم بمكانتهم الاقتصادية والأدبية خاصةً بعد أن خرجوا بتجارتهم من المحيط المحلي إلى النطاق العالمي مسنودة باتفاقيات الإيلاف وما تطلبته من التاني

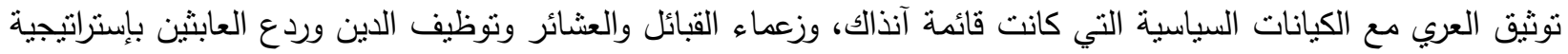
قريش في صنع وحفظ السلم.

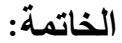

بعد أن استقرت قبيلة قريش في مكة المكرمة واحترفت التجارة وطورت النظام القبلي في حكومة الملأ، أدارت الدينة المقسة إدارة جماعية وأرست قواعد الأمن، سخرت كل شيء لخدمة التجارة باعتبارها سبيل كسب العيش الوحيد في تلك البيئة

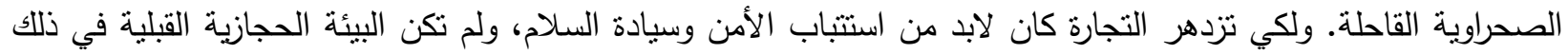
الوقت موطأه لمتل هذه الدفاهيم، فسكان جزيرة العرب آنذاك بدو لا يعرفون إلا قانون الغاب، والحياة كلها داميةٌ بين الناب لابل

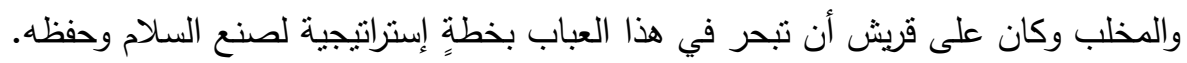
تمكن القرشيون فعلاً بعد منتصف القرن الخامس الميلادي، أي قبل قرنٍ من البعثة النبوية من رسم خطة إستراتيجية لصنع

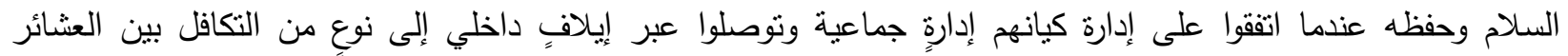

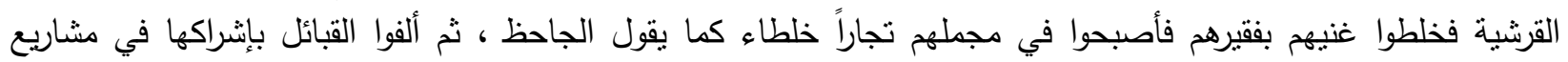
تجارية وتوظيف الدين ليتسع لكافة القبائل العربية وعن طريق الأحلاف والمصاهرات تكمن القرشيون من توسيع نطاق الأمن

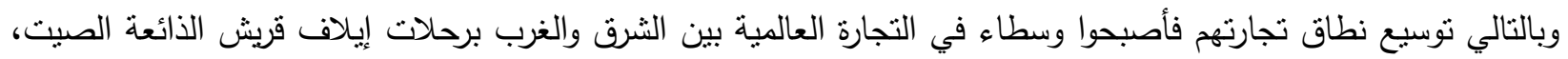

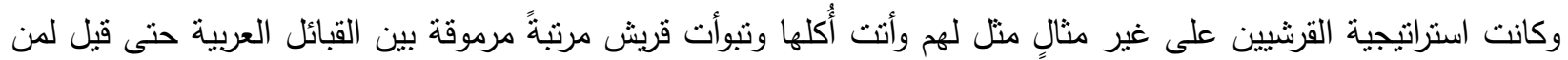

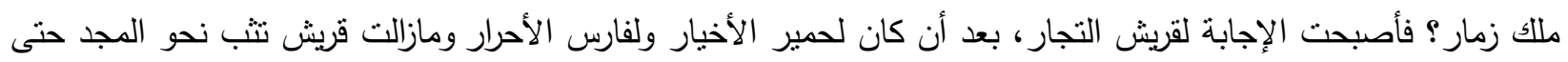

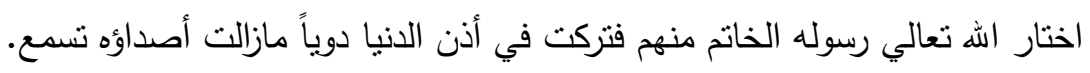
النتائج والتوصيات:

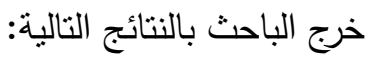
1. أن السلام والأمن ضروريان لازدهار التجارة ونمو الحضارة. 2. ابتدعت قريش إستراتيجية خاصة بها لصنع السلام وحفظه. 3. طبقت قريش هذه الإستراتيجية بنجاح في جميع مراحل تطورها منذ قيام الكيان القرشي وحتى انتشار الإسلام.

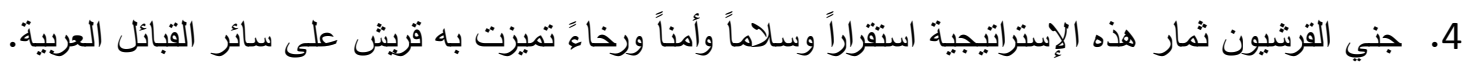




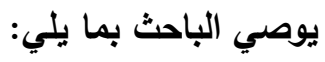

1. لا بد من دراسة تاريخ العرب الاقتصادي والاجتماعي قبل الإسلام لأنه أهمل طويلا برغم أهيته البالغة.

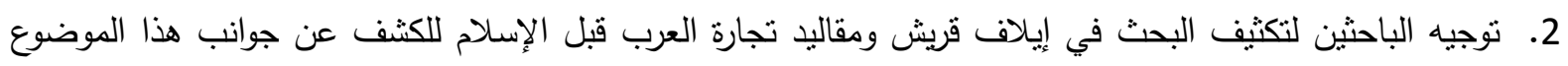

المهم وتأثيره المباشر كأحد مكونات الحضارة الإسلامية.

3. توجيه الباحثن في الدراسات التاريخية للعناية بالجوانب الاقتصادية والاجتماعية والثقافية في إطار التاريخ العام.

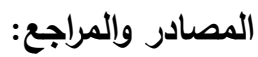

(1) سعيد الحربي، معالم الجزيرة وأماكن الحج والمناسك، تحقيق حمد الجاسر - دار اليمامة الرياض، 1969 ص19-21

(2) محمد بن عبداله الأزرقي، أخبار مكة وما جاء فيها من الآثار ، دار الأندلس 1967، 22/2

(4) الحربي، معالم الجزيرة، مصدر سابق صالف39

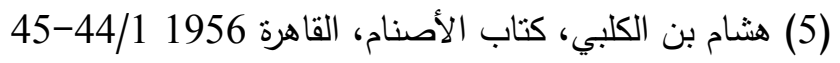

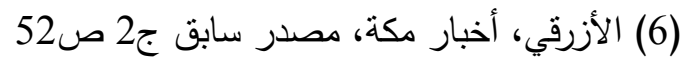

53/1 (7) ابن رستة، الأعلاق النفيسة، ط بريل ليدن 1991 (7)

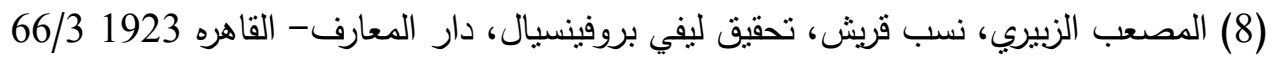

(9) ابن حبيب، المنمق في اخبار قريش، نحقيق خورشيد أحمد فاروق، المطبعة العثمانية 1963 22/1

17/1 ابن خلدون، مقدمة ابن خلدون، طبعة بولاق 1348 (10)

173/2 111 الهذذاني، صفة جزيرة العرب، تحقيق محمد علي الأكوع، دار اليمامة- الرياض 1973

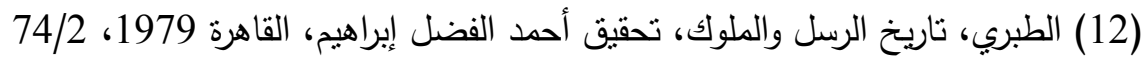

C M Douthy, Travels in Arabia Deserts, Cambridge 1888 Vol.2 p..102 (13)

247/1 الفاسي، شفاء الغرام بأخبار البلد الحرام، القاهرة 1956 (14)

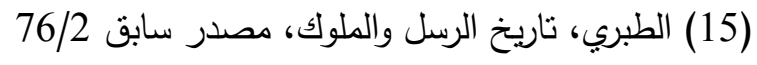

(16) مرنضى الزيبدي، تاج العروس في شرح جواهر القاموس، القاهرة 1356هـ، مادة مكة

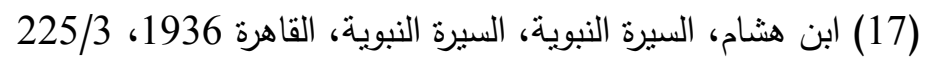

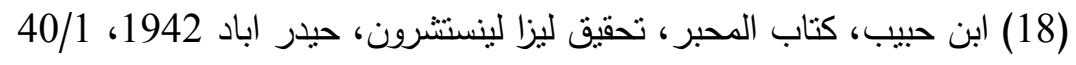

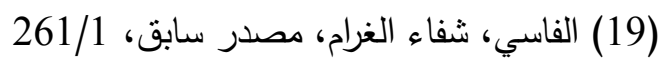

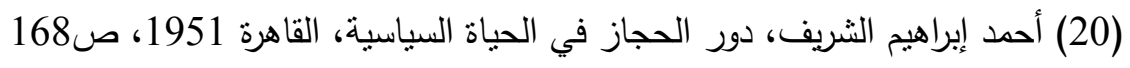

Dozy, encyclopedia of Islam, Leyden1931m Vol.7 p.311 (21) 
De Gaury, Rulers of Mecca, London 1951, p.143-144(22)

$$
\begin{aligned}
& \text { (23) الالوسي، بلوغ الأرب، القاهرة 1934، 202/1 } \\
& \text { (24) ابن الكلبي، كتاب الأصنام، مصدر سابق، 282/2 } \\
& \text { (25) النويري، نهاية الأرب في فنون الأدب، القاهرة 1956، 15/7 } \\
& \text { (26) ابن حبيب، كتاب المحبر ، مصدر سابق، 159/1 }
\end{aligned}
$$

H.Gibb, Arabic lit., London 1923, Vol.1 P.259 (27)

$$
\text { (28) حمد الجاسر، طرق الحجاز ، مجلة الدارة- الرياض 1984، 94/2 }
$$$$
\text { (29) بندلي دوزي، بحث مجمع اللغة العربية، بغداد 1971، 230/3 }
$$$$
\text { (30) الجاحظ، الرسائل، مصدر سابق }
$$$$
\text { (31) ابن هثام، السيرة النبوية، مصدر سابق، 108/1 }
$$

(32) الجاحظ، رسائل الجاحظ، مصدر سابق، 277/2-279

$$
\text { (33) السهيلي، الروض الأنف، مصدر سابق، 155/4 }
$$$$
\text { (34) القاسمي، شفاء الغرام، مصدر سابق، 213/1 }
$$$$
\text { (35) ابن هشام، السيرة النبوية، مصدر سابق، 117/1 }
$$

M. Neibour, Travels Throw Arabia, Edinburgh 1972 P.26(36)

$$
\begin{aligned}
& \text { (37) إبراهيم بيضون، الايلاف القرشي، مرجع سابق، ص61 } \\
& \text { (38) الهمذاني، صفة جزيرة العرب، مصدر سابق، 214/2 } \\
& \text { (39) الألوسي، بلوغ الأرب، مصدر سابق، 227/1 }
\end{aligned}
$$

(40) ابو الفرج الأصفهاني، كتاب الأغاني، القاهرة 1971، 121/9

$$
\text { (41) سورة النور، آية37، انظر البرهان في علوم القرآن للإمام الزركثي، ط- دارا التراث- القاهرة 1957، 151/1 }
$$$$
\text { (42) البخاري، الجامع الصحيح، ط- ليدن 1863، 13/9 }
$$

$$
\text { (43) الطبري، تاريخ الرسل والملوك، ط-4- القاهرة 1979، 134/2 }
$$

$$
\text { 361/1 (44) السهيلي، الروض الأنف، مصدر سابق، }
$$$$
\text { 248/1 ابن هثام، السيرة النبوية، مصدر سابق، }
$$$$
\text { (46) ابن الكلبي، كتاب الأصنام، مصدر سابق، 142/3 }
$$

$$
\text { (47) اليعقوبي، تاريخ اليعقوبي، مصدر سابق، 126/1 }
$$

H.Lammense, Les Alahabish et L'Organisation Militaire de La Meque, Journal Asiatique, (48) 
(49) ابن منظور ، لسان العرب، بيروت 1963، مجلد2 مادة تحش (50) جواد علي، الدفصل في تاريخ العرب قبل الإسلام، بيروت 1981، 199/4 (52) الطبري، تاريخ الرسل والملوك، مصدر سابق، 252/3

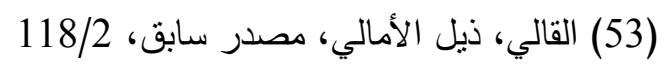
131/2 (54) نفسها

(55) البخاري، الجامع الصحيح، ط-بريلدن 1862 نسخة مصورة، 217/5 (56) ابن هشام، السيرة النبوية، مصدر سابق، 187/1 203/1 نفسها

(58) الجاحظ، رسائل الجاحظ، مصدر سابق، 79/2

(59) اليعقبي، تاريخ اليعقوبي، مصدر سابق، 